\title{
Os primeiros 80 dias da pandemia da COVID-19 em Belo Horizonte: da contenção à flexibilização
}

The first 80 days of the COVID-19 pandemic in the city of Belo Horizonte: from containment to reopening

\author{
Mônica Viegas Andrade (1), Kenya Noronha (1), \\ Cassio Maldonado Turra (1), Gilvan Guedes (1), \\ Fernanda Cimini (1), Leonardo Costa Ribeiro(1), \\ Américo Tristão Bernardes (2), Edson Domingues (1), \\ Mirian Martins Ribeiro (2), Laura de Almeida \\ Botega(1), Lucas Resende de Carvalho(1), \\ Daniel Nogueira (1), Julia Almeida Calazans (1), \\ Nayara Abreu Julião("), Aline de Souza (1), \\ Valéria Andrade Silva (1), Victor Hugo Lima(1),
}

\section{Abstract}

The paper examines the implications of Covid-19 pandemic for the city of Belo Horizonte $(\mathrm{BH})$, during the first 80 days of the disease. We use a descriptive-analytical approach to estimate the growth of Covid-19 cases over time, the excess of deaths, the virus' rate of transmissibility, and the consequent burden on the municipal the health system, measured by the rate of occupancy of public hospital beds. Also, we identify the main containment policies adopted by local authorities, and the implications of reopening measures and the following reduction of social distancing. Our findings reveal that a well-managed Unified Health System (SUS) is paramount to effectively tackle the pandemic and its consequences for the population. The reopening process has imposed new challenges that will require close monitoring by the authorities and by the society.

\section{Keywords}

COVID-19; pandemic; coronavirus, Belo Horizonte; Unified Health System.

JEL Codes H7; I10; I18; I38.
Jéferson Pereira Andrade (1), Monique Felix Ferreira (3), Reinaldo Onofre dos Santos (4), Jomara Alves da Silva (5)

(1) Universidade Federal de Minas Gerais (2) Universidade Federal de Ouro Preto (3) Secretaria de Estado de Saúde de Minas Gerais (4) Secretaria Municipal de Planejamento Orçamento e Gestão de Belo Horizonte

(5) Secretaria Municipal de Saúde de Belo Horizonte

\section{Resumo}

Este artigo examina o contexto e as implicações da pandemia por Covid-19 na cidade de Belo Horizonte (BH) nos primeiros 80 dias da doença. Utilizamos um recorte analítico descritivo para mensurar a evolução dos casos, o excesso de óbitos, a taxa de transmissibilidade do vírus e a pressão da doença sobre o sistema de saúde de BH e região, através da taxa de ocupação hospitalar nos leitos públicos. Além disso, identificamos as principais políticas de contenção adotadas pelas autoridades locais, bem como as implicações da redução do distanciamento social. Nossos resultados demonstram que o Sistema Único de Saúde (SUS), bem gerido, é fundamental para o enfrentamento da pandemia e a mitigação de suas consequências para a população. O processo de flexibilização que se inicia tem imposto novos desafios que requererão monitoramento atento das autoridades e da sociedade.

\section{Palavras-chave}

COVID-19, pandemia, coronavirus, Belo Horizonte, Sistema Único de Saúde.

Códigos JEL H7; I10; I18; I38. 


\section{Introdução}

O enfretamento da pandemia da COVID-19 impôs desafios importantes para os gestores públicos. A resposta à crise envolve necessariamente ações multidimensionais que incluem a criação de um marco normativo específico, a organização de um sistema de vigilância, a gestão e ampliação da capacidade do sistema, políticas específicas de treinamento dos recursos humanos, e a compra de insumos e equipamentos de proteção (CONASS/ CONASEMS, 2020; Oliveira et al., 2020). A presença de sistemas de saúde públicos e universais, como é o caso do Sistema Único de Saúde (SUS) no Brasil, pode favorecer uma resposta satisfatória para essa crise. Por possuírem sistemas de vigilância e de informação organizados, sistemas de saúde públicos e universais permitem o melhor monitoramento da epidemia assim como uma estrutura de oferta organizada e territorializada (Oliveira et al., 2020). O Brasil já apresentou capacidade de resposta a outras epidemias, por exemplo, a H1N1 em 2009 e o Zika Vírus em 2015-2016, demonstrando potencial para o enfrentamento da COVID-19 (Croda et al., 2020). Essa capacidade, entretanto, não é homogênea no território nacional haja vista a disparidade regional na organização dos serviços ofertados pelo SUS (Botega et al., 2020). O colapso do sistema de saúde durante essa epidemia verificado em localidades do Norte e Nordeste do país evidencia essas desigualdades (Noronha et al., 2020).

A pandemia da COVID-19 ampliou o papel dos estados e municípios na condução do enfrentamento da crise uma vez que as políticas locais são fundamentais na definição das medidas de distanciamento social e na gestão da capacidade do sistema (Moraes, 2020a; Harzheim et al., 2020). Nos primeiros 80 dias da pandemia da COVID-19 no Brasil, Belo Horizonte $(\mathrm{BH})$ se destacou como uma das capitais com resultados satisfatórios nesse enfrentamento (Parreiras, 2020; Alves, 2020). Essa performance favorável da capital já foi observada anteriormente no caso da gripe pandêmica de 1918 (Starling, 2020).

O objetivo do presente artigo é avaliar o contexto da pandemia da COVID-19 e suas implicações em BH nos primeiros 80 dias. Esse período cobre os dias entre 17 de março e 05 de junho e compreende as políticas de contenção e o início da primeira fase de flexibilização. $O$ estudo é um recorte analítico descritivo que aborda as principais medidas institucionais implementadas, a evolução dos casos infectados, a pressão sobre o siste- 
ma de saúde de $\mathrm{BH}$ e região e seus desdobramentos em relação ao número de óbitos. Em relação ao sistema de saúde público, BH é o polo estadual e se destaca na oferta de serviços de média e alta complexidade (Bastos et al., 2019) com elevada resolubilidade (Parra, 2019). Relativamente a outras capitais, BH apresenta elevada cobertura da Estratégia de Saúde da Família (ESF), tem tradição na gestão do sistema municipal, implementando todos os instrumentos disponíveis no SUS para organização de uma rede de cuidados (Turci et al., 2019; Morici; Barbosa, 2013) e se destaca na eficiência da gestão do gasto público de saúde (Silva, 2018; Andrade et al., 2017; Vasconcelos; Silva, 2018). Portanto, o presente artigo é uma oportunidade de analisar a resposta apresentada pelo SUS numa cidade brasileira que já tinha, antes da pandemia, um sistema de saúde com uma organização bem estabelecida.

Ao longo do artigo, percorremos três grandes questões: como as medidas institucionais foram estruturadas pelas autoridades locais e qual foi a resposta da população do município em termos de distanciamento social? Como ocorreu a evolução dos casos confirmados de COVID-19 e qual foi sua respectiva taxa de transmissibilidade? Quais foram as consequências da doença do ponto de vista da taxa de ocupação hospitalar e de mortalidade na capital? Esses são os principais eixos de monitoramento das políticas de vigilância da COVID-19 utilizados no mundo todo (Emanuel et al., 2020; Tsai et al., 2020; WHO, 2020). Para lidar com todas essas perguntas, as seções de metodologia e resultados, apresentadas a seguir, estão estruturadas segundo quatro grandes conjuntos de indicadores: medidas institucionais e de distanciamento social, casos, hospitalizações e óbitos. A articulação desse conjunto amplo de indicadores permite oferecer uma visão crítica sobre a gestão de saúde pública em $\mathrm{BH}$ em tempos de pandemia, bem como alertar sobre os desafios que já surgem frente à inevitável flexibilização das medidas de contenção.

\section{Metodologia}

\subsection{Medidas institucionais e de distanciamento social}

Realizamos o levantamento das principais medidas legais promulgadas em $\mathrm{BH}$ e Região Metropolitana (RMBH) entre 03 de março e 05 de junho, 
publicadas em fontes oficiais dos governos estadual e municipais (sites de prefeituras e secretarias de saúde) e em fontes secundárias (mídias sociais). Concentramos as buscas em quatros eixos principais: prevenção à exposição viral; medidas de expansão da capacidade do sistema de saúde; estratégias de mitigação com foco nas medidas econômicas e governança. Essa classificação é baseada na tipologia proposta por Peña et al. (2020). A eventual ausência de alguma medida pode ocorrer devido à natureza manual da busca e dos graus de disponibilidade e clareza em relação às medidas adotadas ao enfrentamento da pandemia em seus canais oficiais.

Além das medidas institucionais, avaliamos o grau de distanciamento social disponibilizado pela empresa Inloco (https://www.inloco.com.br/) por município, no período entre 09 de fevereiro e 05 de junho. $O$ coeficiente de distanciamento social refere-se ao número de usuários de telefone celular que não deixaram seu local de residência, em determinado dia, em relação ao total de usuários. O deslocamento é computado caso ocorra visita a algum estabelecimento por no mínimo 05 minutos ou a 40 metros do local de residência.

\subsection{Evolução dos casos de COVID-19}

A evolução da pandemia nos primeiros 80 dias foi avaliada com base nas informações relativas aos casos de COVID-19, extraídas do sítio Brasil.io (https://brasil.io/home/). Os casos confirmados foram corrigidos usando o fator de subnotificação estimado para Minas Gerais (MG), com base na metodologia proposta por Ribeiro e Bernardes (2020). Estimamos o índice de subnotificação por semana epidemiológica para MG, cobrindo os dias 23 de fevereiro de 2020 a 05 de junho de 2020. A correção dos casos confirmados considerou o índice estimado para a semana anterior devido à defasagem no registro de internação por Síndrome Respiratória Aguda Grave (SRAG).

A partir dessas informações, construímos dois indicadores - taxa de infecção e taxa de transmissibilidade instantânea, $\mathcal{R}_{t}$, que foram calculados para $\mathrm{BH}$, Microrregião de saúde BH-Nova Lima-Caeté (BH-NL-Caeté) e Macrorregião de saúde Centro. A taxa de infecção foi obtida pelo quociente entre número de casos corrigidos e população. As estimativas populacionais para 2020 foram realizadas por Freire (2019). 
A estimativa do $\mathcal{R}_{t}$ utilizou uma abordagem Bayesiana conforme Flaxman et al. (2020). A série do $\mathcal{R}_{t}$ foi segmentada em duas partes: período sem transmissão comunitária e com transmissão comunitária. Para o período sem transmissão comunitária, utilizamos o valor de $\mathcal{R}_{t}=\mathcal{R}_{0}=2,66$, estimado pelo modelo SEIR-D de Máxima Verossimilhança para MG sob um cenário de quarentena estendida (Domingues et al., 2020). Para o período com transmissão comunitária, supusemos $\mathcal{R}_{t} \sim \mathcal{N}^{+}\left(\mu=2.66, \sigma^{2}=|\kappa|\right)$, $\kappa \sim \mathcal{N}(0,1)$. Como desconhecemos o volume e a composição exata dos tipos de testes aplicados em $\mathrm{BH}$ e região, assumimos que a variância segue uma distribuição normal, com o dobro da variância utilizada em Flaxman et al. (2020). A estimação do $\mathcal{R}_{t}$ depende também do intervalo serial $(\tau)$, cuja informação sobre a sua distribuição não está disponível para BH e região. Testamos duas especificações para suas distribuições a priori: paramétrica determinística e baseada em reamostragem por Monte Carlo. Nas duas especificações, supusemos uma distribuição a priori lognormal conforme $\mathrm{He}$ et al. (2020): $\ln (\tau) \sim \mathcal{N}\left(\mu_{\tau}=1,43, \sigma_{\tau}^{2}=0,66\right)$. No processo de amostragem dos parâmetros $\mu_{\tau}$ e $\sigma_{\tau}$, utilizamos $n_{\tau}=10.000$ amostras de $\left(\mu_{\tau}, \sigma_{\tau}\right)$ com a amostragem iniciando-se em $\mu_{\tau}^{(k)}$ e, então, $\sigma_{\tau}^{(k)}$ com a restrição $\mu_{\tau}^{(k)}<\sigma_{\tau}^{(k)}$. Apresentamos a série temporal da distribuição a posteriori de $\mathcal{R}_{t}$ para ambas as estratégias paramétricas com janela de 14 dias, ${ }^{1}$ considerando intervalo de credibilidade de $95 \%$ centrais. $\bigcirc \mathcal{R}_{t}$ foi estimado a partir dos casos diários observados e corrigidos. A série temporal utilizada se inicia em 24 de abril, para a Microrregião BH-NL-Caeté e BH, e a partir de 16 de abril para a Macrorregião Centro, data em que essas localidades tinham, pelo menos, 10 óbitos confirmados por COVID-19.

\subsection{Pressão sobre o sistema de saúde}

Realizamos um exercício de simulação para avaliar em que medida a estrutura de oferta observada antes da pandemia seria capaz de atender a demanda extra gerada pela COVID-19. Estimamos taxas de ocupação simuladas para BH, Microrregião BH-NL-Caeté e Macrorregião Centro. As estimativas foram realizadas para leitos gerais, leitos UTI e aparelhos de ventilação assistida, considerando três cenários de taxas de infecção

1 A janela de 7 dias foi testada e os resultados estão disponíveis sob requisição. 
$(0,01 \%, 0,1 \%$ e $1 \%)$ e três cenários de tempo (1, 3 e 6 meses). Calculamos as taxas de ocupação com base na razão entre o total de dias de permanência hospitalar (considerando a demanda de internações em 2019 e internações por COVID-19) e o número de dias disponíveis da oferta de leitos (geral e UTI) e aparelhos de ventilação mecânica em cada cenário de tempo e de taxa de infecção. As internações realizadas no SUS em 2019 foram extraídas do Sistema de Informações Hospitalares (SIH). As informações sobre a oferta de leitos e aparelhos de ventilação mecânica, referentes a dezembro de 2019, foram obtidas no Cadastro Nacional de Estabelecimentos de Saúde (CNES). Excluímos os leitos obstétricos, pediátricos, hospital-dia e especiais para leitos gerais, e os leitos pediátricos, neonatal e queimados para leitos UTI. Os leitos excluídos não são facilmente convertidos para o atendimento da COVID-19.

Seguindo Noronha et al. (2020), obtivemos o número de dias de permanência de internações decorrentes da COVID-19 ao multiplicar as internações devido à COVID-19 pelo tempo médio de permanência hospitalar segundo o nível de agravo: 8 dias para casos mais leves (leitos gerais) e 10 dias para casos mais graves (leitos UTI e aparelhos de ventilação mecânica). Devido à indisponibilidade de informações, supusemos que a taxa de ocupação dos leitos privados era igual à média estimada para o SUS em cada Micro/Macrorregião em 2019. Realizamos duas simulações: uma considerando os leitos SUS e privados, outra incluindo apenas leitos SUS. Calculamos a demanda por internações gerada pela COVID-19 em duas etapas. Na primeira, obtivemos o número esperado de casos confirmados por idade ao multiplicar as taxas de infecção pela proporção da população, ambas por grupo etário, em cada localidade de análise. Normalizamos os valores obtidos de forma a totalizarem taxas de infecção equivalentes a $0,01 \%, 0,1 \%$ e $1 \%$ da população. Na segunda, multiplicamos o número esperado de casos pelas taxas específicas por grupo de idade de internação geral ou UTI para obter o número total de internações em cada grupo etário. Adotamos como padrão as taxas específicas por idade de infecção, internação geral e UTI estimadas para os Estados Unidos (CDC, 2020). Detalhes metodológicos das simulações estão em Noronha et al. (2020).

Para o monitoramento da pandemia, avaliamos a evolução da taxa de ocupação observada nos primeiros 80 dias na capital. Essa informação reflete não só a pressão gerada pela taxa de infecção já observada, 
mas também as medidas que foram adotadas para ampliar a capacidade de atendimento, como expansão da oferta de leitos e postergação de cirurgias eletivas. As taxas de ocupação hospitalar foram disponibilizadas pela Secretaria Municipal de Saúde de Belo Horizonte (SMSA-BH) entre 04 de maio, quando a série histórica passou a ser organizada, até o dia 07 de junho, e referem-se a leitos totais, excluídos os leitos de acolhimento noturno, oftalmológicos, CTR doenças infecciosas-AIDS, psiquiátricos, de captação de órgãos e leitos do Hospital Sara Kubitscheck. Obtivemos também as informações de leitos UTI de campanha em BH, referentes a maio de 2020 (códigos 51 e 52), conforme registros do CNES.

\subsection{Excesso de óbitos}

Os dados de óbitos para residentes de MG foram extraídos do Sistema de Informações de Mortalidade (SIM), sendo selecionados apenas os não fetais ocorridos por causas naturais, organizados segundo as semanas epidemiológicas. Para os anos de 2014 a 2018, foram utilizadas as informações disponíveis no Departamento de Informática do Sistema Único de Saúde (DATASUS). Os dados de 2019 e 2020, anonimizados e ainda preliminares, foram fornecidos pela SES-MG. Foram geradas pela SES-MG duas versões dos dados preliminares de 2020 - 15 de maio e 04 de junho - para examinar a estabilidade das informações ao longo do tempo, já que os dados são atualizados com o envio de novos casos pelas secretarias municipais. A comparação entre as duas versões sugere que o registro do número de óbitos já se encontra relativamente estável para $\mathrm{BH}$ até a $14^{\mathrm{a}}$ semana epidemiológica de 2020. Na maioria dessas semanas, o incremento foi inferior a $0,5 \%$, atingindo $2,4 \%$ na $14^{\mathrm{a}}$ semana.

Segundo a Portaria 116/2020 do Ministério da Saúde (MS), as secretarias de saúde devem garantir a transferência dos dados até 60 dias após o encerramento do mês de ocorrência. Portanto, ainda não é possível assegurar o mesmo nível de qualidade para os óbitos ocorridos nas semanas 15 a $23 \mathrm{em} \mathrm{BH}$, período que compreende parte importante dos primeiros 80 dias da pandemia. Além disso, as variações entre as duas versões da base de dados foram significativamente maiores para a Microrregião BH-NL-Caeté, Macrorregião Centro, e para a totalidade de MG. Portanto, a análise se limita aos óbitos de residentes de BH para as semanas epidemio- 
lógicas 03 a 14, nos anos de 2014 a 2020. Essas semanas correspondem, em 2020, ao período entre 12 de janeiro e 04 de abril. Como forma de garantir segurança às estimativas, não examinamos o comportamento dos óbitos por causas de morte específicas, tampouco por idade ou sexo.

Realizamos duas análises para o cálculo do excesso de óbitos naturais totais (Leon et al. 2020). Na primeira, comparamos o número de óbitos ocorridos nas semanas epidemiológicas 03 a 14 em 2020 com a série histórica de óbitos ocorridos nas semanas 03 a 43 nos anos anteriores (2014 a 2019), bem como com a média semanal de óbitos para o período 2014-2019. Na segunda abordagem, realizamos uma análise matemática da evolução temporal dos óbitos para as semanas 03 a 14, seguindo Ribeiro e Bernardes (2020). Obtivemos uma função que repete, com alto grau de confiabilidade (coeficiente de correlação linear acima de 0,9), o comportamento típico dos óbitos para BH no período entre 2014 a 2019. Esse comportamento foi extrapolado para 2020, representando o número de óbitos esperado, caso não houvesse alterações no padrão de mortalidade causado por um aumento atípico dos óbitos. Por fim, calculamos a diferença entre a função extrapolada para 2020 e o número de óbitos notificados no SIM, bem como seu percentual em relação ao número esperado de óbitos.

\section{Resultados}

\subsection{Principais políticas de enfrentamento da COVID-19 e indicado- res de distanciamento social}

No dia 06 de fevereiro, o governo federal sancionou a Lei no 13.979, que dispõe sobre as medidas de enfrentamento à COVID-19 a serem adotadas pelas autoridades no âmbito de suas competências, tais como: a) isolamento dos casos confirmados e suspeitos; b) quarentena; c) restrição de mobilidade; d) realização compulsória de procedimentos, e e) dispensa temporária de licitação para a compra de bens, insumos e serviços de saúde destinados ao combate ao novo coronavírus.

Em conformidade à Lei, MG decretou estado de emergência em saúde pública (Decreto n 113, de 12/03/2020), quatro dias após a confirmação do primeiro caso. Em 15 de março, foi instituído o comitê responsável pelo 
acompanhamento do quadro epidemiológico da doença e delineamento das medidas para o enfrentamento da pandemia. Cinco dias depois, com a confirmação de transmissão comunitária no estado, o governador decretou estado de calamidade pública (Decreto n 47.891, de 20/03/2020). Entre as principais medidas adotadas, destacam-se a suspensão das atividades não essenciais e de aulas presenciais; a criação de leis para a abertura de crédito especial destinados a programas de saúde; o uso obrigatório de máscara em locais públicos; benefícios temporários à prestação de assistência alimentar às famílias de estudantes da rede pública. ${ }^{2}$

Em Belo Horizonte, a primeira medida implementada foi a inauguração do Centro Especializado em COVID-19, uma unidade inteiramente dedicada ao atendimento de pacientes com sintomas de doenças respiratórias. No dia 17 de março, um dia após a confirmação do primeiro caso na cidade, a Prefeitura de Belo Horizonte ( $\mathrm{PBH}$ ) declarou emergência em saúde pública e criou o comitê de Enfrentamento à Epidemia da COVID-19, responsável pelo acompanhamento da curva de contaminação e pelas medidas de saúde pública no município (Decreto n 17.298/2020). As primeiras medidas de distanciamento social foram adotadas na mesma semana, com o cancelamento das aulas na rede municipal de ensino e a suspensão de eventos públicos e privados com potencial de aglomeração. A paralisação do comércio e outras atividades não essenciais teve início no dia 20 de março (Decreto $\left.n^{\circ} 17.304 / 2020\right)$. Outras medidas preventivas, como o fechamento dos parques municipais e desinfecção de pontos estratégicos da cidade foram realizadas (Figura 1).

Para aumentar a capacidade de resposta dos sistemas de saúde, além da criação de dois centros especializados para COVID-19, determinou-se o cancelamento dos procedimentos médicos eletivos, a ampliação dos serviços de saúde on-line e a abertura de contratação temporária de médicos e enfermeiros. Em relação às medidas de proteção social e econômica, a prefeitura realizou a distribuição de cestas básicas às famílias de estudantes da rede pública e a comunidades tradicionais e promoveu o acolhimento emergencial da população em situação de rua e grupos vulneráveis com suspeita ou confirmação da doença. Para atenuar os efeitos negativos da pandemia sobre o setor produtivo, foi prorrogada a cobrança das taxas de

2 Nessa ordem: Deliberação n ${ }^{\circ} 17$, de 22/03/20; Deliberação n 15 , de 20/03/2020; Deliberação n 11, de 20/03/2020; Lei n² 23.632, de 02/03/2020; Lei no 23.636, de 17/04/2020; Decreto $\mathrm{n}^{\circ} 47.915$, de 10/04/2020. 
fiscalização de localização e funcionamento. Com o avanço no número de casos, ao final do mês de abril, algumas medidas se tornaram mais rigorosas, como a restrição de mobilidade intermunicipal e o uso obrigatório de máscara em locais públicos (Figura 1).

Embora as medidas de enfrentamento ao novo coronavírus estejam sendo adotadas de forma descentralizada, observa-se convergência entre as decisões tomadas pela capital e pelos municípios da RMBH, que decretaram Emergência em saúde pública a partir da segunda quinzena de março e adotaram medidas de distanciamento social, variando em grau de rigidez e temporalidade. A partir da segunda quinzena de abril e início de maio, todos os municípios da $\mathrm{RMBH}$ passaram a exigir o uso obrigatório de máscaras. Além das medidas de prevenção, alguns municípios também adotaram ações importantes de infraestrutura e apoio social e econômico aos cidadãos (Quadro 1).

Ao final de abril, MG começou a entrar em nova fase. O programa "Minas Consciente - retomando a economia do jeito certo", adotado em 23 de abril, criou critérios para a reabertura progressiva no Estado, orientando prefeitos quanto à adoção de protocolos sanitários que garantam a proteção da população à exposição viral. O programa setoriza as atividades em quatro "ondas", a partir de uma matriz de risco que considera aspectos econômicos e da rede assistencial. A adesão ao programa ficou a cargo dos prefeitos, que são responsáveis pela regulamentação das atividades econômicas locais e devem considerar a realidade de sua Macrorregião de saúde. Desde então, muitos municípios da RMBH deram início à reabertura parcial das atividades não essenciais.

$\mathrm{Na}$ capital, um grupo de trabalho para avaliação e planejamento da reabertura da economia, composto pelos secretários municipais de saúde, desenvolvimento econômico, fazenda e planejamento, foi instituído no dia 27 de abril (Decreto $n^{\circ}$ 17.348/2020). A primeira etapa de flexibilização das atividades econômicas e, por conseguinte, início do afrouxamento do isolamento social começou a ocorrer no dia $25 / 05$ por efeito do Decreto $\mathrm{n}^{\circ}$ 17.361/2020, de 22/05/2020. No dia 08 de junho, BH deu início à segunda etapa de flexibilização do comércio. Mais duas etapas de flexibilização, previstas até a reabertura total da economia, estão condicionadas aos indicadores epidemiológicos, que podem sugerir progressão, permanência ou regressão de fase. 
Figura 1 Linha do tempo das principais medidas de enfrentamento ao COVID-19 adotadas em Belo Horizonte até o dia 05 de junho de 2020

\begin{tabular}{|c|c|}
\hline $03 / 03 / 2020$ & Inauguração do Centro Especializado em COVID-19 (CECOVID) \\
\hline $16 / 03 / 2020$ & Primeiro caso confirmado \\
\hline $17 / 03 / 2020$ & $\begin{array}{l}\text { Situação de emergência em saúde pública e Criação do Comitê de Enfrentamento à Epidemia da } \\
\text { COVID-19 em BH }\end{array}$ \\
\hline \multirow[t]{2}{*}{$18 / 03 / 2020$} & Suspensão dos procedimentos de saúde eletivos \\
\hline & $\begin{array}{l}\text { Suspensão temporária dos Alvarás de Localização e Funcionamento e autorizações para realização de } \\
\text { atividades com potencial de aglomeração }\end{array}$ \\
\hline \multirow[t]{4}{*}{$19 / 03 / 2020$} & Interrupção das atividades escolares nas escolas municipais e creches parceiras \\
\hline & Instituição do teletrabalho (empregados da PBH) \\
\hline & Adoção de medidas e ações preventivas de contaminação nos serviços de transporte público \\
\hline & $\begin{array}{l}\text { Prorrogação/parcelamento do pagamento das taxas de fiscalização de localização e funcionamento, } \\
\text { de fiscalização sanitária e de fiscalização de engenhos de publicidade }\end{array}$ \\
\hline \multirow[t]{2}{*}{$20 / 03 / 2020$} & $\begin{array}{l}\text { Fechamento de equipamentos esportivos/lazer, parques municipais, centros de Vivência Agroecológi- } \\
\text { ca e Jardim Zoológico e Botânico }\end{array}$ \\
\hline & $\begin{array}{l}\text { Recomendações para adequação das atividades das Unidades de Pronto Atendimento e Serviço de } \\
\text { Atendimento Móvel de Urgência }\end{array}$ \\
\hline $21 / 03 / 2020$ & $\begin{array}{l}\text { Determinação de condições temporárias e especiais de saúde e vigilância sanitária para atividades de } \\
\text { teleatendimento, central de telemarketing e call center }\end{array}$ \\
\hline $23 / 03 / 2020$ & Início das ações de desinfecção de pontos estratégicos da cidade \\
\hline $25 / 03 / 2020$ & Abertura do Centro de Doenças Respiratórias/COVID-19 \\
\hline $29 / 03 / 2020$ & Primeiro óbito por COVID-19 \\
\hline $30 / 03 / 2020$ & $\begin{array}{l}\text { Contratação de médicos e enfermeiros por tempo determinado para atender necessidade excepcional } \\
\text { de interesse público }\end{array}$ \\
\hline \multirow[t]{3}{*}{$31 / 03 / 2020$} & Proibição da realização de velórios, sepultamentos restritos aos familiares \\
\hline & $\begin{array}{l}\text { Orientações para profissionais de saúde sobre casos sintomáticos respiratórios ou contatos domicilia- } \\
\text { res de pacientes sintomáticos }\end{array}$ \\
\hline & $\begin{array}{l}\text { Início da distribuição de cestas às famílias de estudantes da rede municipal e de alimentos para } \\
\text { comunidades tradicionais }\end{array}$ \\
\hline $01 / 04 / 2020$ & $\begin{array}{l}\text { Recomendações para adequação das atividades desenvolvidas na Atenção Primária à Saúde e na Rede } \\
\text { de Atenção Psicossocial à Saúde }\end{array}$ \\
\hline \multirow[t]{2}{*}{$03 / 04 / 2020$} & Recomendações para pacientes e familiares sobre isolamento domiciliar por suspeita de COVID-19 \\
\hline & $\begin{array}{l}\text { Orientações sobre o cuidado à pessoa idosa em contexto da COVID-19 para população em geral e } \\
\text { profissionais de saúde }\end{array}$ \\
\hline $06 / 04 / 2020$ & $\begin{array}{l}\text { Início de acolhimento provisório e emergencial para pessoas em situação de rua e outras vulnerabili- } \\
\text { dades sociais com suspeita ou confirmação de COVID-19 }\end{array}$ \\
\hline $08 / 04 / 2020$ & $\begin{array}{l}\text { Proibição da circulação em BH de transporte público coletivo de municípios que interromperem as } \\
\text { medidas de isolamento social }\end{array}$ \\
\hline
\end{tabular}




\section{Figura 1 (continuação)}

\begin{tabular}{|c|c|}
\hline \multirow[t]{2}{*}{$08 / 04 / 2020$} & $\begin{array}{l}\text { Implantação de medidas preventivas em estabelecimentos do setor privado não atingidos pela } \\
\text { restrição de funcionamento }\end{array}$ \\
\hline & Orientações para a Vigilância Epidemiológica da COVID-19 \\
\hline $09 / 04 / 2020$ & $\begin{array}{l}\text { Distribuição de kits de higiene e ampliação de cestas básicas para pessoas em maior vulnerabilidade } \\
\text { econômica e social }\end{array}$ \\
\hline $10 / 04 / 2020$ & $\begin{array}{l}\text { Instituição da grade de referência da Rede de Urgência e Emergência e definição das diretrizes de } \\
\text { transferências pré-hospitalares e hospitalares no SUS }\end{array}$ \\
\hline $13 / 04 / 2020$ & $\begin{array}{l}\text { Ampliação do número de consultas para o atendimento on-line da população com sintomas de } \\
\text { COVID-19 }\end{array}$ \\
\hline $15 / 04 / 2020$ & Instalação de pias em pontos estratégicos da cidade para pessoas em situação de rua \\
\hline $16 / 04 / 2020$ & Determinação do uso de máscaras e restrição do acesso de clientes em estabelecimentos comerciais \\
\hline $21 / 04 / 2020$ & Declaração de estado de calamidade pública \\
\hline $27 / 04 / 2020$ & $\begin{array}{l}\text { Instituição de grupo de trabalho para avaliar e planejar a reabertura gradual e segura dos setores que } \\
\text { tiveram atividades suspensas }\end{array}$ \\
\hline $30 / 04 / 2020$ & Distribuição de verbas para unidades de acolhimento para ações contra a COVID-19 \\
\hline $11 / 05 / 2020$ & $\begin{array}{l}\text { Orientações ao Núcleo de Atendimento às Medidas Socioeducativas e Protetivas e Centro de Referên- } \\
\text { cia Especializado de Assistência Social }\end{array}$ \\
\hline \multirow[t]{2}{*}{$14 / 05 / 2020$} & Determinação da instalação de pontos de fiscalização sanitária \\
\hline & Entrega de máscaras para população de aglomerados \\
\hline \multirow[t]{2}{*}{$19 / 05 / 2020$} & Ampliação da distribuição de cestas básicas para feirantes \\
\hline & Ampliação de testes para verificar imunidade da população à COVID-19 \\
\hline $21 / 05 / 2020$ & $\begin{array}{l}\text { Recomendações para adequação das atividades dos serviços de reabilitação em situação de surtos/ } \\
\text { epidemias de Síndrome Gripal e infecção pelo SARS-CoV-2 }\end{array}$ \\
\hline \multirow[t]{4}{*}{$22 / 05 / 2020$} & Reabertura gradual dos setores que tiveram as atividades suspensas, a partir do dia 25 de maio \\
\hline & Medidas voltadas à prevenção no serviço público de transporte coletivo de passageiros por ônibus \\
\hline & Protocolos gerais e específicos de vigilância sanitária para as atividades autorizadas a funcionar \\
\hline & Recomendações para realização de testes rápidos para os profissionais de segurança pública \\
\hline $25 / 05 / 2020$ & $\begin{array}{l}\text { Orientações às equipes de referência dos Serviços Socioassistenciais de Proteção Social Especial } \\
\text { para Pessoas em Situação de Rua sobre busca ativa e orientação aos beneficiários do Programa Bolsa } \\
\text { Família, que irão acessar o Auxilio Emergencial do governo federal }\end{array}$ \\
\hline \multirow[t]{2}{*}{$27 / 05 / 2020$} & Programa Família Acolhedora receberá $R \$ 30$ mil do Fundo da Criança e do Adolescente \\
\hline & $\begin{array}{l}\text { Recomendações para notificação de resultados de exames para COVID-19 por laboratórios privados e } \\
\text { drogarias de BH }\end{array}$ \\
\hline \multirow[t]{2}{*}{$01 / 06 / 2020$} & Prefeitura inicia consulta de cestas básicas e kits de higiene de junho \\
\hline & Homologação de resultado e pagamento a empreendedores culturais \\
\hline $05 / 06 / 2020$ & Início da fase 2 de reabertura do comércio \\
\hline
\end{tabular}


Figura 2 Distanciamento social médio semanal (\%) para Minas Gerais, Macrorregião Centro, Microrregião BH-NL-Caeté e Belo Horizonte

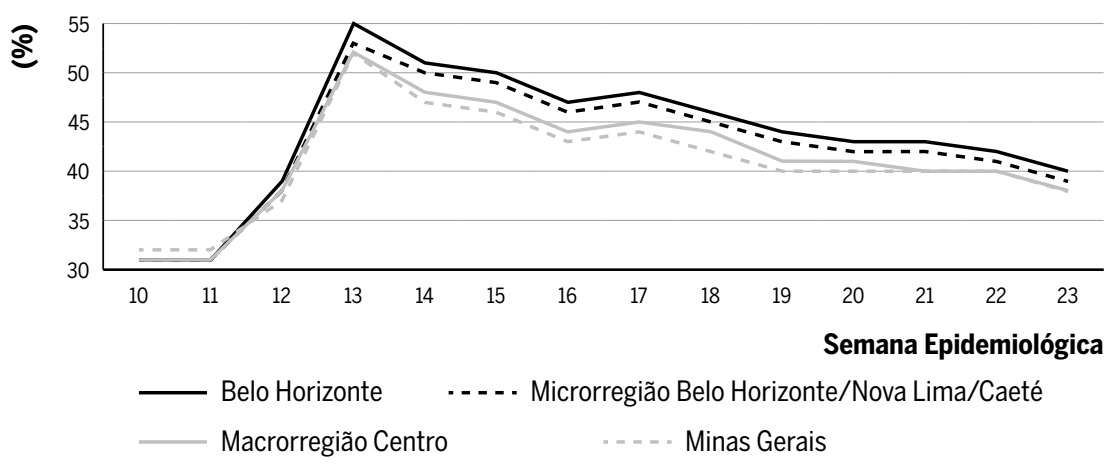

Fonte: Brasil.io; Inloco.

As medidas de distanciamento social e a posterior flexibilização se refletiram diretamente no comportamento da população, sobretudo na capital. A partir da $12^{\text {a }}$ semana epidemiológica (15 a 21 de março), a média de distanciamento social aumentou no Estado e na Macrorregião Centro, sendo maior na Microrregião BH-NL-Caeté, principalmente em $\mathrm{BH}$. Na capital, devido à paralização do comércio e outras atividades, o nível de distanciamento social atingiu seu máximo na $13^{\mathrm{a}}$ semana, 55\%, oscilando até a $17^{\mathrm{a}}$ semana entre $47 \%$ e $50 \%$. A partir desse período, a média se reduziu gradualmente, mas os níveis permaneceram expressivamente maiores para BH. Após o Decreto no 17.361/2020 da $\mathrm{PBH}$, houve queda mais acentuada do distanciamento, alcançando $39 \%$ ao final do período analisado. Esse percentual, apesar de menor do que a média observada desde a implementação das primeiras medidas de isolamento, superava a média do período pré-pandemia, que era próxima de 30\% (Figura 2).

\subsection{Evolução dos casos de COVID-19 em Belo Horizonte e região}

Belo Horizonte foi o quinto município em MG a confirmar a doença, com o primeiro caso confirmado em 16 de março, e o primeiro a identificar transmissão comunitária (origem de contaminação não rastreável), em 17 de março. Desde então, a Microrregião de Saúde BH-NL-Caeté lidera o número de casos no Estado e na sua Macrorregião, sobretudo devido à trajetória da doença em BH (Figura 3, painéis a e b). A marca dos 100 casos foi alcançada 


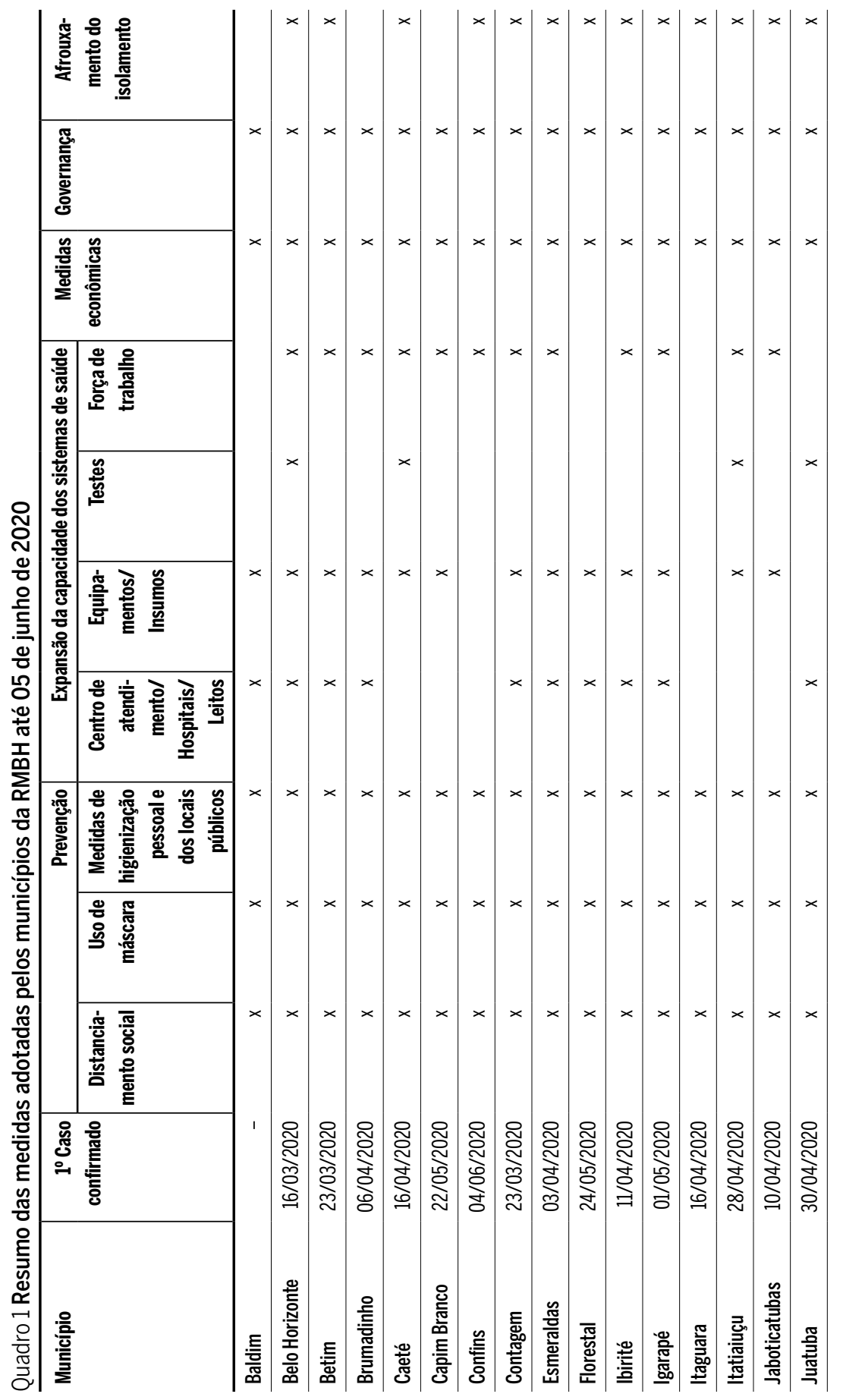




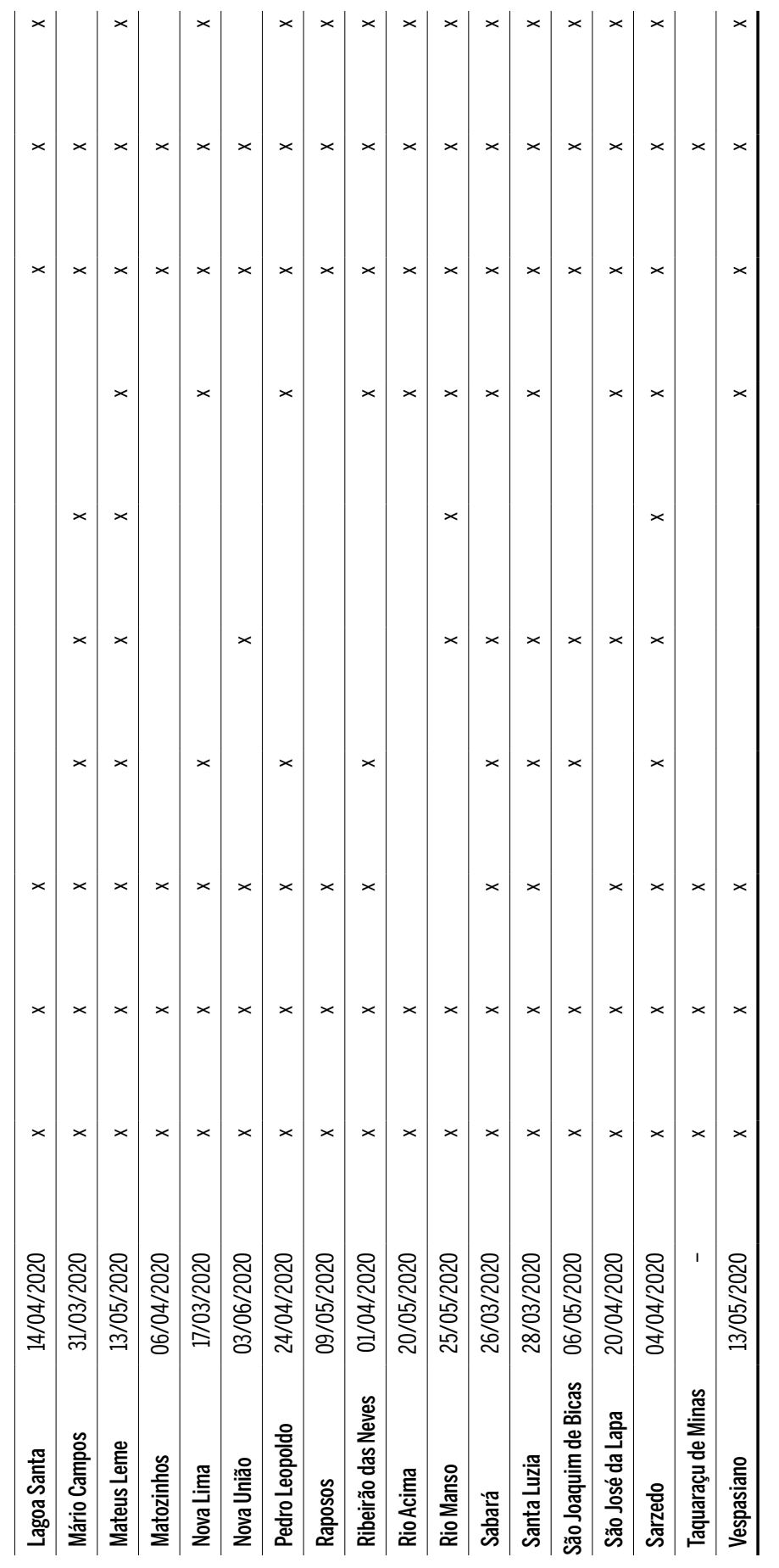




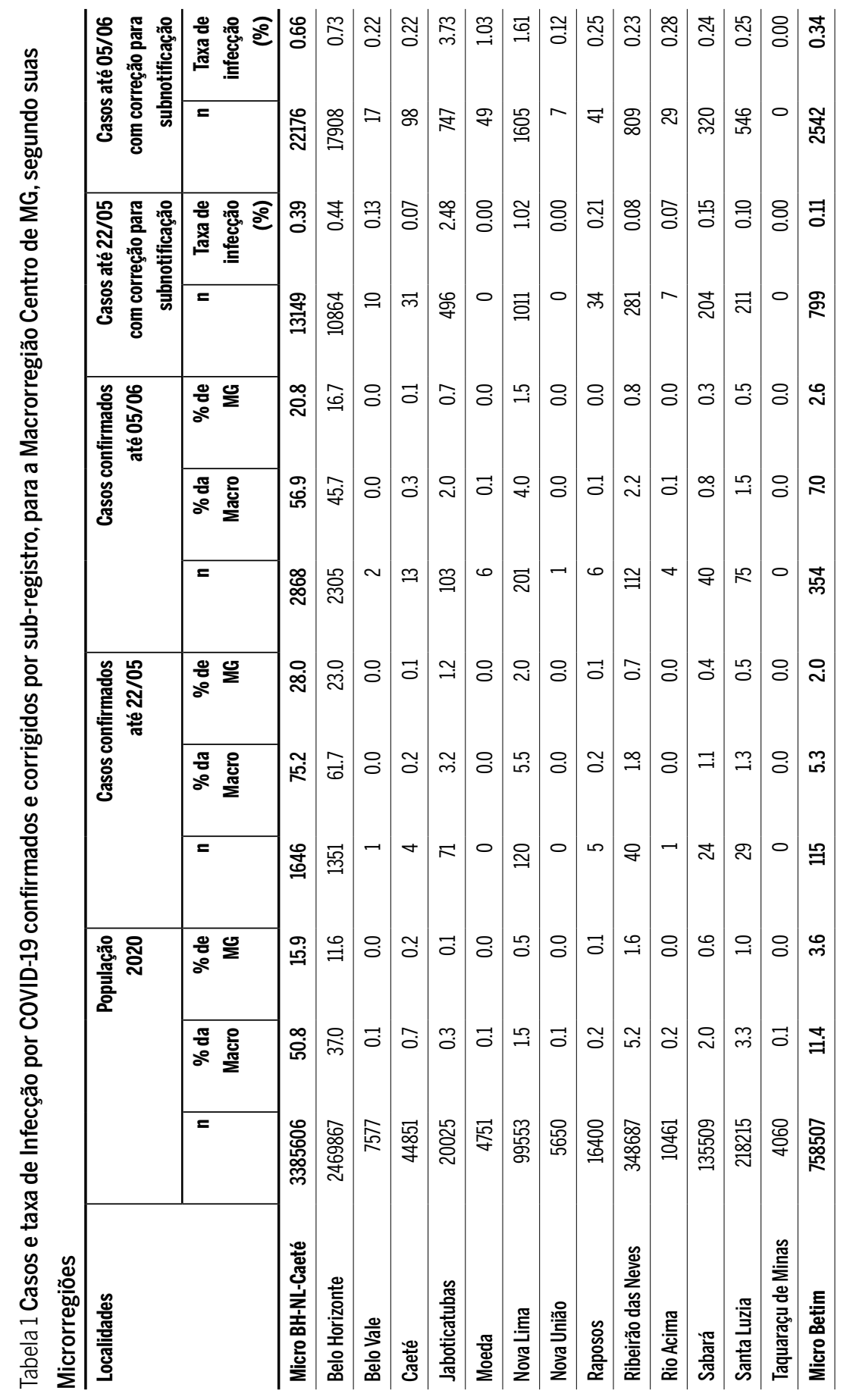




$$
\begin{aligned}
& \text { 商 }
\end{aligned}
$$

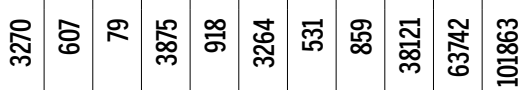

$$
\begin{aligned}
& \text { 경 농 응 궁 旁 }
\end{aligned}
$$

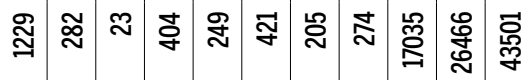

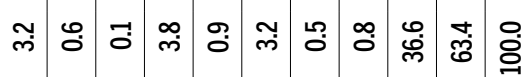

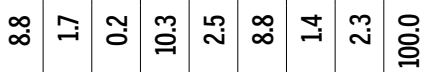

$$
\begin{aligned}
& \text { ஐ }
\end{aligned}
$$

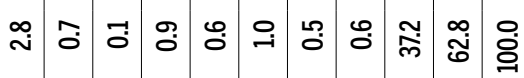

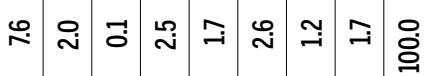

$$
\begin{aligned}
& \text { 导 } \\
& \text { ₹ } \text { ㅇㅇㅇ }
\end{aligned}
$$

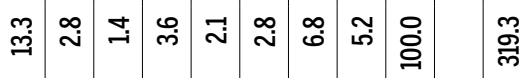

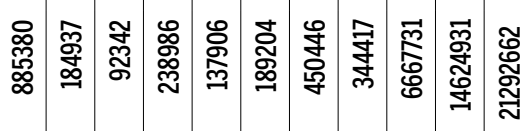

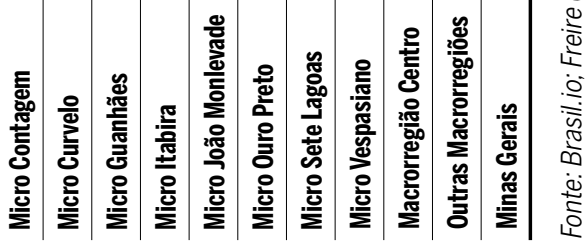


em 10 dias na referida Microrregião, quando foram registrados 107 casos ( $92 \%$ do total da Macrorregião Centro e 36\% do estado), sendo 96 na capital, e a marca dos 1.000 casos em 53 dias na Microrregião e 58 dias em BH.

A Microrregião BH-NL-Caeté, que detém $51 \%$ da população da Macrorregião Centro, era, em 22 de maio, responsável por cerca de $75 \%$ dos casos da Macrorregião e $28 \%$ do Estado. BH era o município com maior peso (61,7\% dos casos da Macrorregião), seguido por Nova Lima (5,5\%) e Jaboticatubas (3,2\%). Duas semanas após a flexibilização, o peso da Microrregião BH-NL-Caeté, com 2.868 casos, caiu para 56,9\% da Macrorregião e para 20,8\% no estado, em função do aumento dos casos em outras Microrregiões da própria Macro, como Itabira e Ouro Preto (Tabela 1, Figura 3, painéis a e b).

Quanto às taxas de infecção, estimadas com base em casos corrigidos, a Microrregião BH-NL-Caeté também liderava na sua Macro e no Estado. Os dados acumulados até 22 de maio apontam taxa de 0,39\%, valor acima da taxa da Macrorregião $(0,26 \%)$ e do Estado $(0,20 \%)$ (Tabela 1). Considerando os municípios da Microrregião, até 21 de maio, Nova Lima apresentava a maior taxa, sendo ultrapassada por Jaboticatubas no dia 22 desse mesmo mês. Até essa data, a taxa de infecção nesses dois municípios era igual a 1,02\% e $2,48 \%$, respectivamente (Tabela 1). A capital permaneceu no terceiro lugar no período, com taxa de infecção igual a $0,44 \%$ (Tabela 1, Figura 3, painéis c e d). Apesar de mais elevada que as taxas observadas na Macro e Microrregião, esse percentual mostra um cenário favorável em $\mathrm{BH}$ antes da flexibilização. Em 5 de junho, a taxa de infecção em BH aumentou para 0,73\%, permanecendo acima da média de sua Microrregião e Macrorregião de saúde (Tabela 1).

A variação relativa dos casos semanais confirmados guarda uma relação com o coeficiente de distanciamento social da semana epidemiológica anterior (Figura 3, painel e). Nas semanas 12, 13 e 14 (entre 15 de março e 4 de abril), a variação de novos casos ficou em torno de $90 \%$, reduzindo-se a partir da $15^{a}$ semana, quando o distanciamento da semana anterior alcançou o pico de $55 \%$. A partir da $16^{\text {a }}$ semana, a variação dos novos casos manteve-se relativamente estável, no patamar de $25 \%$ até a $22^{a}$ semana (entre 25 e 30 de maio). Nesse período, a capital apresentou crescimento relativo dos casos abaixo da média de sua Microrregião, Macrorregião e do Estado. $\mathrm{Na} 23^{\mathrm{a}}$ semana, que considera o período de flexibilização das medidas de distanciamento, a variação de novos casos aumentou para $30 \%$ em BH, enquanto a Microrregião se manteve estável. A Macrorregião Centro, em contraste, apresentou variação bem maior (51\%). 
Figura 3 Evolução do número de casos, taxa de infecção por COVID-19 e níveis de isolamento da Macrorregião Centro segundo Microrregiões de Saúde e municípios selecionados da Microrregião BH-NL-Caeté

Painel a Casos (log) das Microrregiões selecionadas da Macrorregião Centro

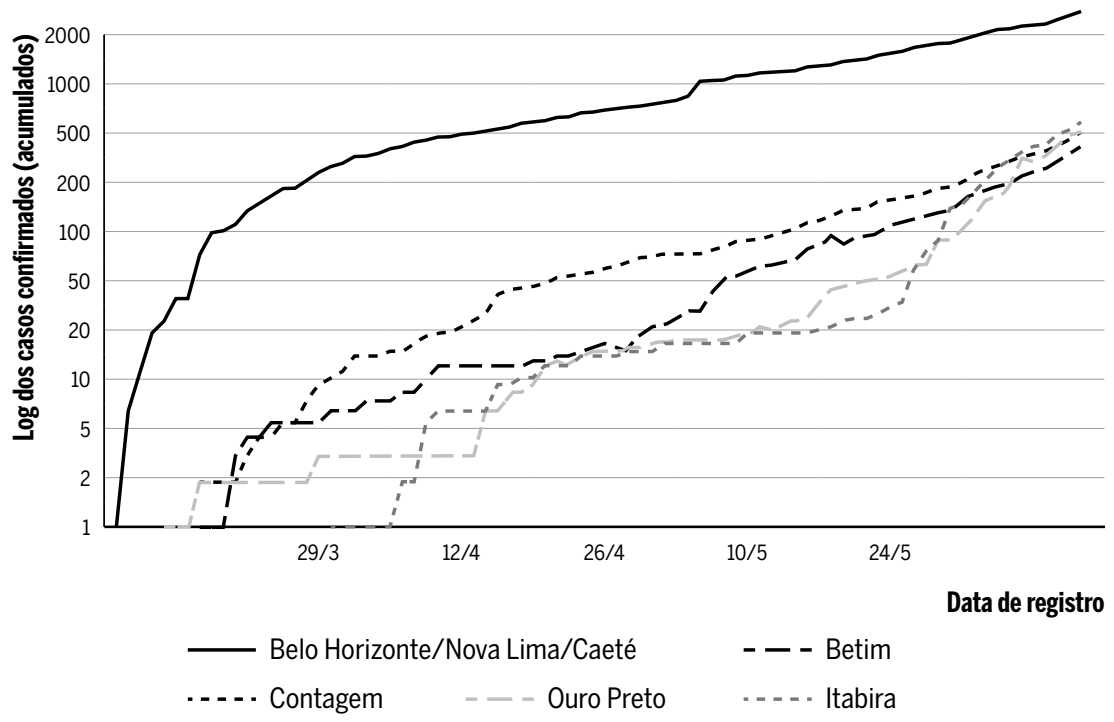

Painel b Casos (log) dos municípios selecionados da Microrregião BH-NL-Caeté

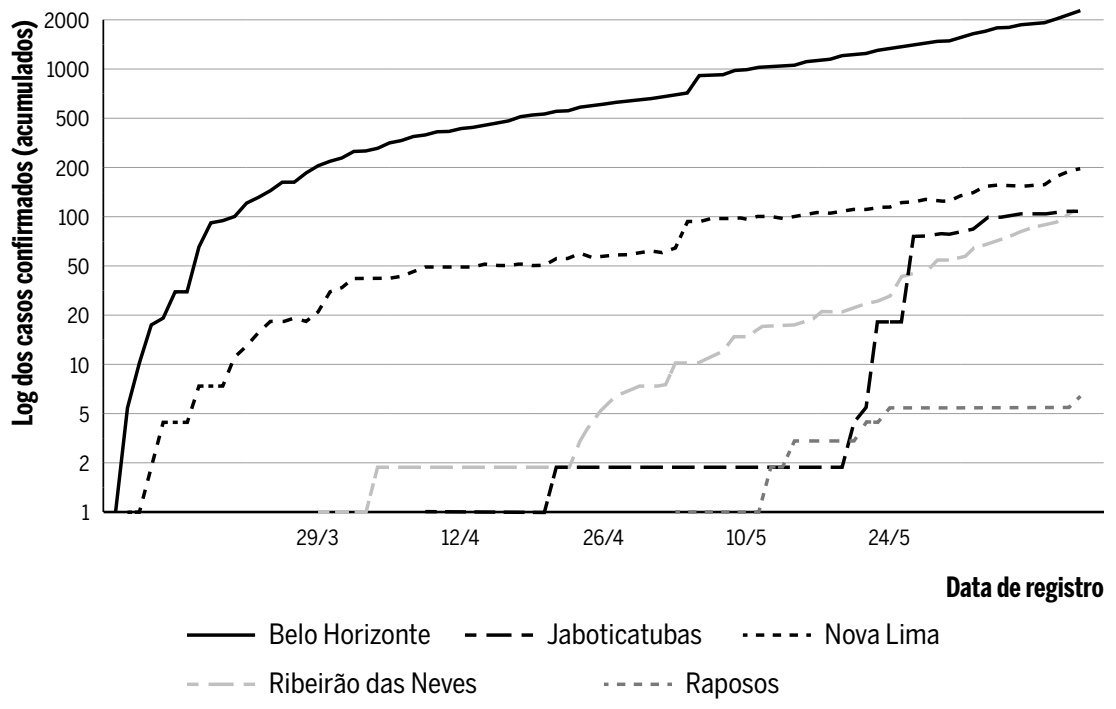


Painel c Taxas de infecção (\%) das Microrregiões selecionadas da Macrorregião Centro

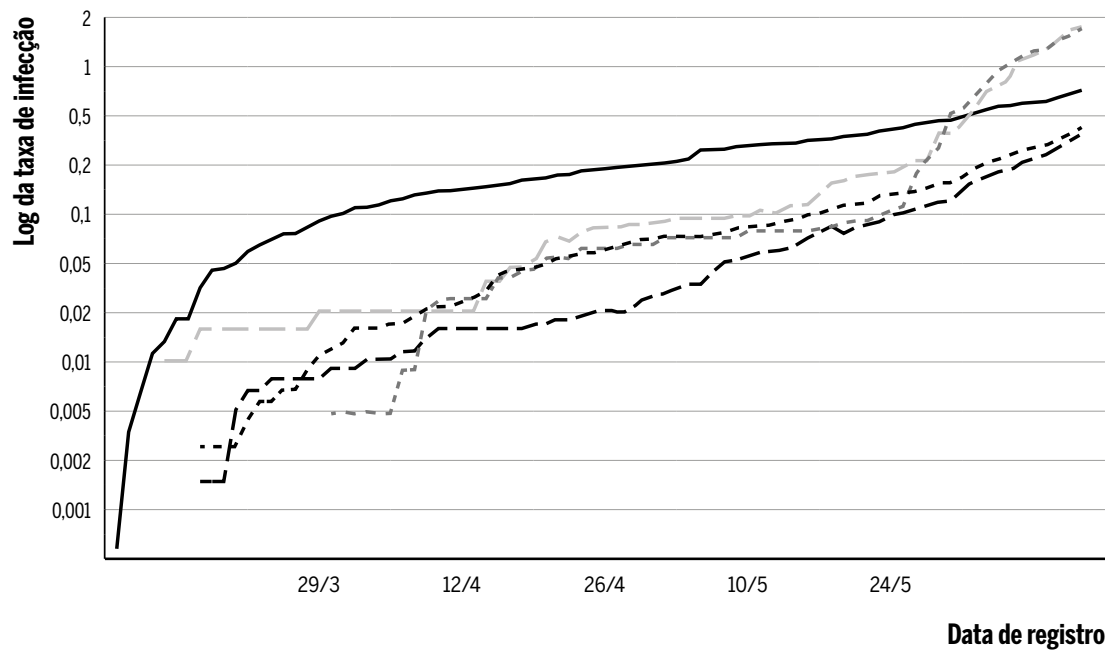

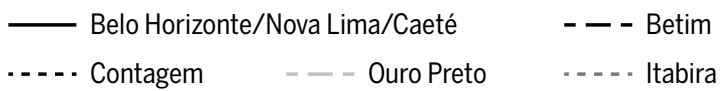

Painel d Taxas de infecção (\%) dos municípios selecionados da Microrregião BH-NL

\section{-Caeté}

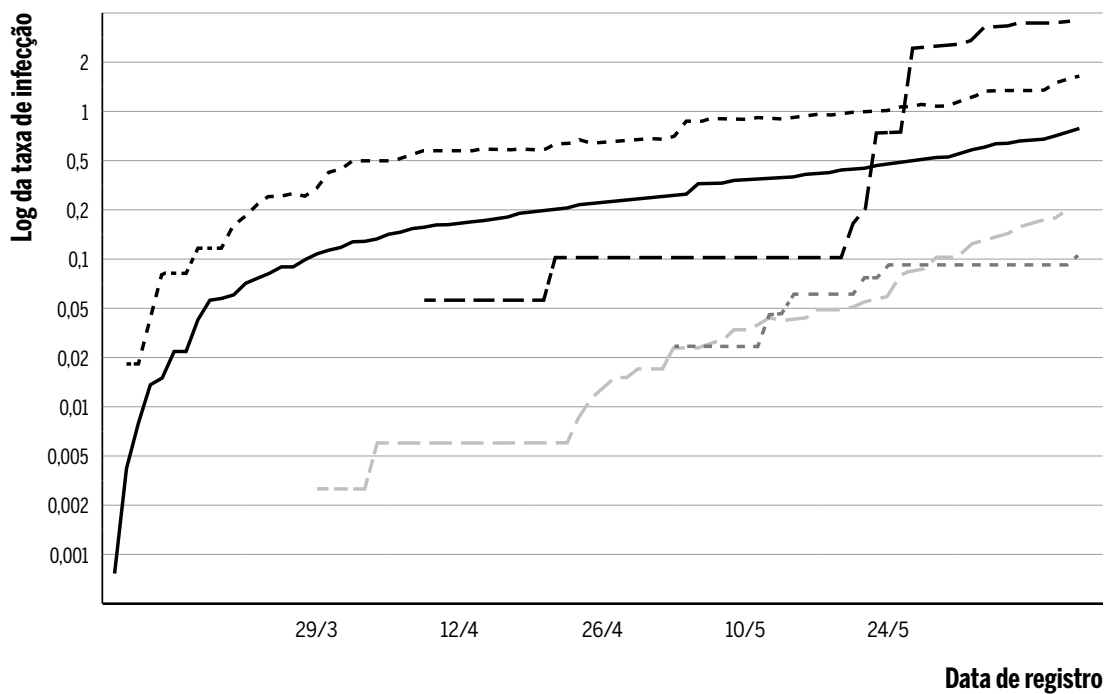

— Belo Horizonte - - - Jaboticatubas - - - - Nova Lima

Ribeirão das Neves [ - - - Raposos 
Painel e Isolamento médio semanal (\%) e variação (\%) de casos notificados para Minas Gerais, Macrorregião Centro, Microrregião BH-NL-Caeté e Belo Horizonte

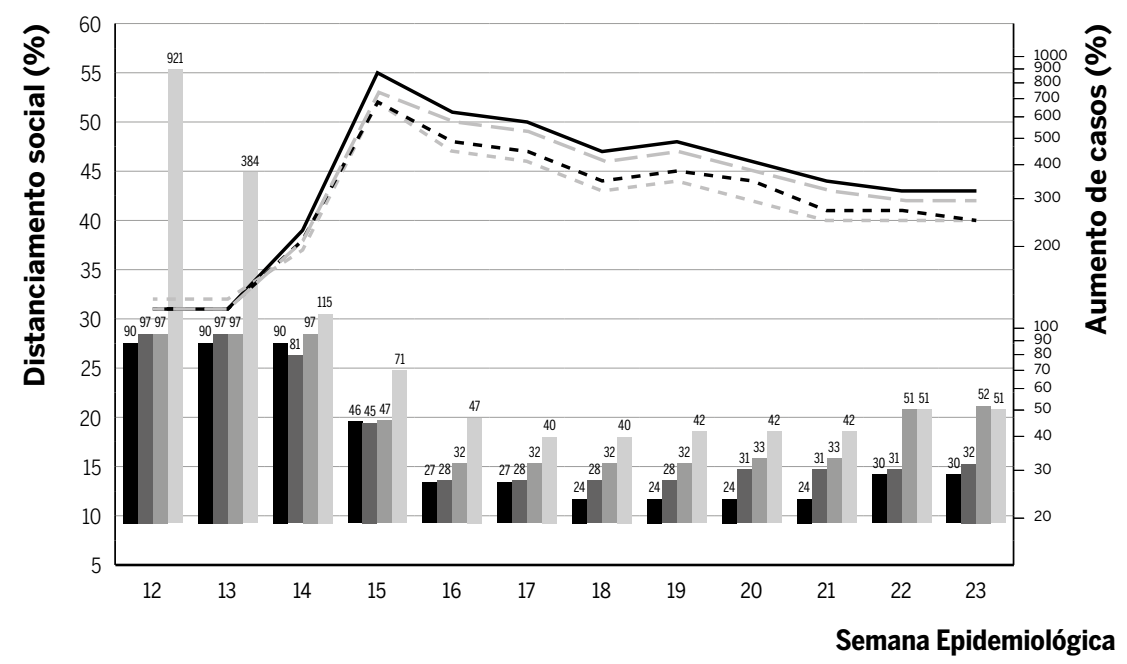

Distanciamento social duas semanas antes

$\square$ Belo Horizonte $-\ldots-$ Microrregião Belo Horizonte/Nova Lima/Caeté
.. _. - Macrorregião Centro
Aumento de casos (\%)
Belo Horizonte $\square$ Microrregião Belo Horizonte/Nova Lima/Caeté
$\square$ Macrorregião Centro

Fonte: Brasil.io; Inloco; Freire et al., 2019. Série de casos confirmados suavizada pelo método Tukey's (Running Median) utilizando o software R versão 3.6.3.

A Figura 4 apresenta o comportamento da mediana a posteriori da taxa de transmissibilidade instantânea da COVID-19 em BH, Micro e Macrorregião, com intervalo central de credibilidade de $95 \%$. Observam-se alguns pontos importantes: (1) $\circ \mathcal{R}_{t}$ manteve-se significativamente abaixo de 2 durante todo o período para $\mathrm{BH}$, Microrregião e Macrorregião; (2) a série para casos observados e corrigidos diferiram-se em alguns pontos do tempo, mas têm se aproximado consistentemente nas últimas semanas; (3) Em BH, verifica-se crescimento do dia 18 de maio até 29 de maio, quando volta a cair, retornando à tendência de aumento a partir do dia 03 de junho. Comportamento similar é observado para a Macrorregião e Microrregião; (4) Na Macrorregião e Microrregião, até o dia 13 de maio, a mediana do $\mathcal{R}_{t}$ se situava em níveis mais baixos, mas a partir dessa data, manteve-se 
sistematicamente mais elevada do que em $\mathrm{BH}$, sinalizando um processo de interiorização da pandemia. A partir do dia 04 de junho, a mediana do $\mathcal{R}_{t}$ em BH superou a da Microrregião, coincidindo com o período de 15 dias após a liberação das atividades econômicas na capital.

Entre os dias 08 de maio e 05 de junho, para $\mathrm{BH}$, o $\mathcal{R}_{t}$ atingiu, em 08 de maio, um valor máximo de 1,59 [95\% CrI = 1,27; 2,08] (dados observados) e de 1,52 [95\% CrI $=1,36 ; 1,69]$ em 29 de maio (dados corrigidos por sub-registro). O valor mínimo foi registrado em 18 de maio para os dados observados $\left(\mathcal{R}_{t}=0,75[95 \% \mathrm{CrI}=0,66 ; 0,83]\right)$ e corrigidos $\left(\mathcal{R}_{t}=0,75[95 \%\right.$ $\mathrm{CrI}=0,71 ; 0,79])$. A transmissibilidade mais recente da série (05 de junho) estava em $1,42[95 \% \mathrm{CrI}=1,30 ; 1,54]$ e $1,40[95 \% \mathrm{CrI}=1,32 ; 1,48]$ para dados observados e corrigidos, respectivamente. Para a Microrregião, o $\mathcal{R}_{t}$ em 05 de junho era de 1,33 e 1,32 para os casos observados e corrigidos, e para a Macrorregião, 1,47 e 1,44, respectivamente.

Figura 4 Taxa de transmissibilidade instantânea da COVID-19 em Belo Horizonte, Microrregião de Saúde BH-NL-Caeté e Macrorregião Centro, 2020

Belo Horizonte

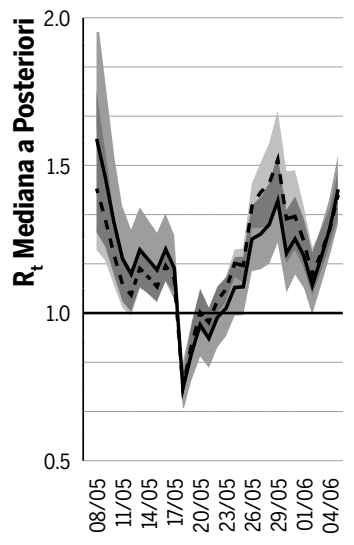

- Casos observados - . - - Casos corrigidos

Fonte: Brasil.io, Inloco.

\section{Microrregião}

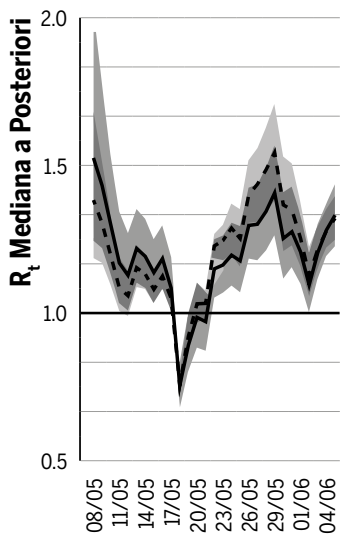

\section{Macrorregião}

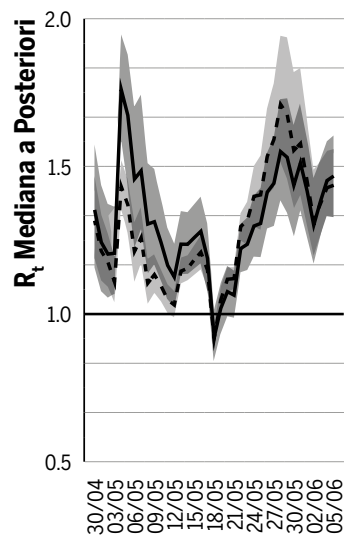




\subsection{Pressão sobre o sistema de saúde}

Os resultados da simulação mostram que a oferta de leitos gerais de dezembro de 2019 seria suficiente para atender a demanda mesmo quando excluímos o setor privado em todos os cenários analisados, exceto na Macrorregião Centro se a taxa de infecção de 1\% fosse alcançada em apenas um mês (Tabela 2). Em relação a leitos UTI, a situação é mais preocupante, especialmente a uma taxa de infecção de $1 \%$, para a qual o colapso do sistema seria observado independentemente da velocidade de propagação do vírus. Nos demais cenários a oferta seria suficiente, mas as taxas de ocupação hospitalar estariam operando em níveis preocupantes. Esses resultados são observados para BH e para as Micro/Macrorregião de saúde. A situação se tornaria particularmente mais dramática se o sistema contasse apenas com a oferta SUS. Os resultados para aparelhos de ventilação mecânica, apesar de menos severos, são similares aos observados para leitos UTI (Tabela 2).

Tabela 2 Percentual de leitos gerais, leitos UTI e aparelhos de ventilação mecânica ocupados considerando taxas de infecção por COVID-19 igual a 0,01\%, 0,1\% e 1\% em cada Micro/Macrorregião de saúde e três horizontes temporais

\begin{tabular}{|c|c|c|c|c|c|c|}
\hline \multirow{2}{*}{$\begin{array}{l}\text { Taxa de infecção e } \\
\text { tempo de propagação }\end{array}$} & \multicolumn{2}{|r|}{ BH } & \multicolumn{2}{|c|}{ Microrregião } & \multicolumn{2}{|c|}{ Macrorregião } \\
\hline & $\begin{array}{r}\text { SUS + } \\
\text { Privado }\end{array}$ & SUS & $\begin{array}{r}\text { SUS + } \\
\text { Privado }\end{array}$ & SUS & $\begin{array}{r}\text { SUS + } \\
\text { Privado }\end{array}$ & SUS \\
\hline \multicolumn{7}{|l|}{ Leitos gerais } \\
\hline \multicolumn{7}{|c|}{ Taxa de infecção de $0,01 \%$} \\
\hline 6 meses & 56.1 & 56.1 & 53.8 & 53.8 & 75.0 & 75.1 \\
\hline 3 meses & 56.1 & 56.2 & 53.8 & 53.9 & 75.1 & 75.2 \\
\hline 1 mês & 56.3 & 56.4 & 54.0 & 54.2 & 75.3 & 75.6 \\
\hline \multicolumn{7}{|l|}{ Taxa de infecção de $0,1 \%$} \\
\hline 6 meses & 56.4 & 56.7 & 54.2 & 54.5 & 75.6 & 76.0 \\
\hline 3 meses & 56.8 & 57.3 & 54.6 & 55.2 & 76.2 & 77.0 \\
\hline 1 mês & 58.2 & 59.7 & 56.3 & 58.2 & 78.7 & 81.1 \\
\hline \multicolumn{7}{|l|}{ Taxa de infecção de 1\% } \\
\hline 6 meses & 59.6 & 62.2 & 58.1 & 61.2 & 81.2 & 85.2 \\
\hline 3 meses & 63.0 & 68.3 & 62.4 & 68.8 & 87.5 & 95.5 \\
\hline 1 mês & 76.9 & 92.7 & 79.9 & 98.8 & 112.5 & 136.6 \\
\hline
\end{tabular}


Tabela 2 (continuação)

\begin{tabular}{l|r|r|r|r|r|r}
\hline Taxa de infecção e & \multicolumn{3}{|c|}{ BH } & \multicolumn{2}{|r}{ Microrregião } & \multicolumn{2}{|r}{ Macrorregião } \\
\cline { 2 - 6 } tempo de propagação & $\begin{array}{r}\text { SUS + } \\
\text { Privado }\end{array}$ & SUS & $\begin{array}{r}\text { SUS + } \\
\text { Privado }\end{array}$ & SUS & $\begin{array}{r}\text { SUS + } \\
\text { Privado }\end{array}$ & SUS \\
\hline
\end{tabular}

\section{Leitos UTI}

\section{Taxa de infecção de $\mathbf{0 , 0 1 \%}$}

\begin{tabular}{lrrrrrr}
\hline 6 meses & 97.7 & 97.7 & 92.7 & 92.8 & 89.6 & 89.7 \\
\hline 3 meses & 97.7 & 97.8 & 92.8 & 92.9 & 89.7 & 89.9 \\
\hline 1 mês & 98.0 & 98.2 & 93.1 & 93.4 & 90.2 & 90.7
\end{tabular}

\section{Taxa de infecção de $0,1 \%$}

\begin{tabular}{lrrrrrr}
\hline 6 meses & 98.2 & 98.6 & 93.4 & 94.0 & 90.6 & 91.5 \\
\hline 3 meses & 98.7 & 99.6 & 94.1 & 95.3 & 91.8 & 93.5 \\
\hline 1 mês & 100.9 & 103.4 & 96.9 & 100.5 & 96.5 & 101.7 \\
\hline
\end{tabular}

Taxa de infecção de $1 \%$

\begin{tabular}{lrrrrrr}
\hline 6 meses & 103.1 & 107.3 & 99.8 & 105.7 & 101.1 & 109.8 \\
\hline 3 meses & 108.6 & 117.0 & 106.9 & 118.8 & 112.8 & 130.1 \\
\hline 1 mês & 130.4 & 155.8 & 135.5 & 171.1 & 159.6 & 211.4 \\
\hline
\end{tabular}

\begin{tabular}{|c|c|c|c|c|c|c|}
\hline \multicolumn{7}{|c|}{ Aparelhos de ventilação mecânica } \\
\hline \multicolumn{7}{|c|}{ Taxa de infecção de $0,01 \%$} \\
\hline 6 meses & 97.7 & 97.7 & 92.7 & 92.7 & 89.5 & 89.6 \\
\hline 3 meses & 97.7 & 97.7 & 92.8 & 92.8 & 89.6 & 89.7 \\
\hline 1 mês & 97.8 & 97.9 & 92.9 & 93.1 & 89.9 & 90.1 \\
\hline \multicolumn{7}{|c|}{ Taxa de infecção de 0,1\% } \\
\hline 6 meses & 98.0 & 98.2 & 93.1 & 93.4 & 90.2 & 90.5 \\
\hline 3 meses & 98.4 & 98.7 & 93.6 & 94.0 & 90.9 & 91.5 \\
\hline 1 mês & 99.8 & 100.8 & 95.5 & 96.8 & 93.8 & 95.7 \\
\hline \multicolumn{7}{|c|}{ Taxa de infecção de 1\% } \\
\hline 6 meses & 101.2 & 102.9 & 97.4 & 99.6 & 96.8 & 99.9 \\
\hline 3 meses & 104.8 & 108.2 & 102.1 & 106.5 & 104.1 & 110.3 \\
\hline 1 mês & 119.2 & 129.2 & 121.1 & 134.2 & 133.3 & 152.0 \\
\hline
\end{tabular}

Fonte: CNES/MS, dez. 2019); SIH/MS, 2019; Centers for Disease Control and Prevention (CDC); Freire, 2019.

Esses resultados ressaltam a importância do controle da pandemia, verificado em $\mathrm{BH}$ e região até o início do período de flexibilização, para atenuar a pressão sobre o sistema de saúde. Em 05 de junho de 2020, a Microrregião BH-NL-Caeté e a Macro Centro enfrentavam taxas de infecção iguais a $0,66 \%$ e $0,57 \%$, respectivamente, valores ainda distantes do cenário de 
$1 \%$, no qual seria observado o colapso do sistema. Além do controle da pandemia, medidas de ampliação da capacidade de atendimento, desconsideradas nos exercícios das simulações, têm sido fundamentais para aliviar a pressão gerada pela COVID-19 no sistema de saúde. Como resposta à pandemia, foram disponibilizados 651 leitos UTI em BH, sendo 621 privados e 30 públicos, além do redirecionamento de leitos específicos para COVID-19 e postergação de cirurgias eletivas.

Essas medidas se traduziram numa situação favorável para o sistema de saúde em BH nesses primeiros 80 dias. A Figura 5 apresenta a evolução da taxa de ocupação dos leitos SUS disponíveis em BH observada entre os dias 04 de maio e 07 de junho. Para os leitos de enfermaria COVID-19, a taxa de ocupação situava-se entre $34 \%$ e $38 \%$ até o dia 26 de maio, aumentando gradualmente a partir dessa data até alcançar $52 \%$ em 07 de junho. Padrão similar era observado para os leitos UTI COVID, que iniciou o período com taxa de 44\%, apresentou dois picos nos dias 14 e 17 de maio (52\%), retornando ao patamar de $45 \%$ até o dia 23 de maio. A partir dessa data, observou-se crescimento progressivo com o processo de flexibilização das atividades econômicas, alcançando $72 \%$ no dia 07 de junho. As taxas de ocupação dos leitos não COVID apresentaram comportamento relativamente estável durante todo o período, tanto para enfermaria $(80 \%-85 \%)$ como UTI $(80 \%-84 \%)$. Essas taxas de ocupação, mais baixas que a média histórica observada em BH, refletem, entre outros, o adiamento dos procedimentos hospitalares eletivos.

Figura 5 Evolução da taxa de ocupação dos leitos em hospitais do SUS do município de Belo Horizonte entre 04 de maio e 07 de junho de 2020

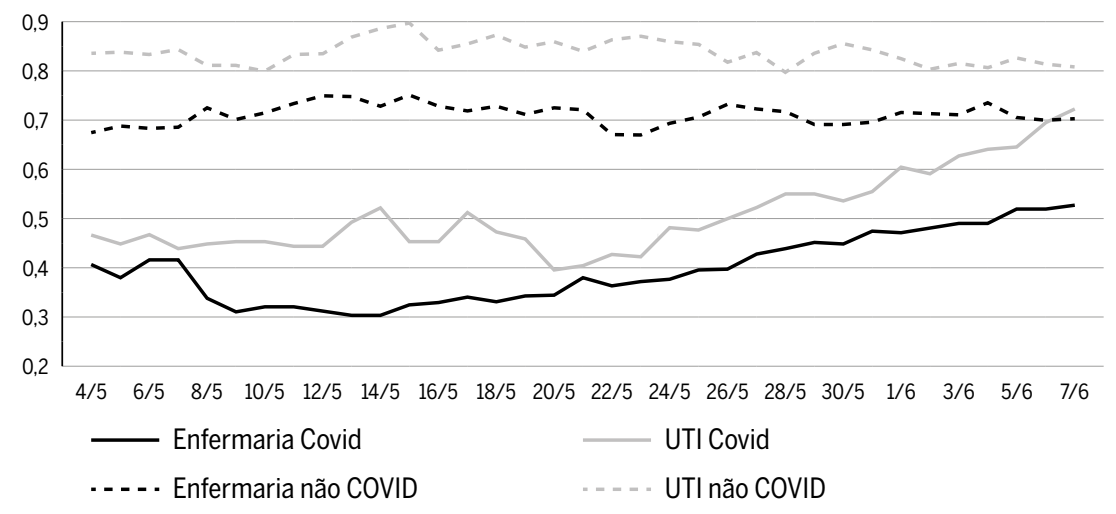

Fonte: SMSA-BH. 


\subsection{Excesso de óbitos}

A Figura 6 apresenta o número de óbitos ocorridos nas semanas epidemiológicas 03 a 14 em 2020, comparado à média e aos valores extremos da série histórica de óbitos ocorridos nas semanas 03 a 43 nos anos anteriores (2014 a 2019). De maneira geral, ocorreram entre 200 e 300 óbitos por semana para os residentes do município nos últimos anos, incluindo 2020. Há variações importantes entre os anos e entre as semanas, o que dificulta uma conclusão mais definitiva a partir, exclusivamente, da análise visual das séries. De todo modo, os resultados parecem sugerir um número de óbitos ligeiramente superior à média histórica na $12^{\mathrm{a}}$ semana epidemiológica de 2020 ( 15 a 21 de março). Há aumento mais significativo no número de óbitos nas semanas 13 e 14, quando ocorreu o primeiro óbito confirmado por COVID-19 em BH (29 de março). Esse número de óbitos é maior, não apenas do que a média histórica, mas também em relação ao valor máximo observado em anos anteriores, podendo ser um prenúncio do crescimento sistemático no número de óbitos no período da pandemia para além do esperado. Vale destacar, entretanto, que na quinta semana, o número de óbitos também foi superior à média histórica e ao valor máximo observado nos anos anteriores.

Figura 6 Número registrado de óbitos por semana epidemiológica, Belo Horizonte, ambos os sexos

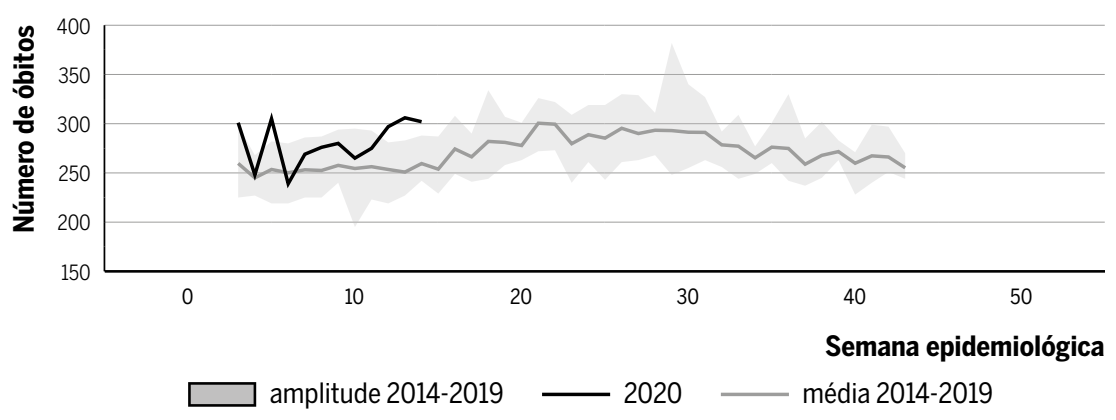

Fonte: SIM/DATASUS/SES-MG.

A Figura 7 apresenta o percentual de óbitos em excesso (desvio \%) e o respectivo desvio padrão, a cada duas semanas epidemiológicas em 2020, em relação ao valor predito pelo modelo estimado com base na tendência 
histórica dos óbitos observados no período 2014-2019. Há, como sugerido pela Figura 6, variações bem marcadas na série de óbitos ao longo do ano, traduzidas pelo modelo em desvios tanto por excesso quanto por falta em relação aos valores esperados. Contudo, destaca-se o excesso no número de óbitos observados em relação aos esperados nas últimas duas semanas de análise, 13 e 14, quando a pandemia já estava presente em BH. O desvio percentual estimado foi igual a $18 \%$, o maior em todas as semanas analisadas, o equivalente a 92 óbitos por causas naturais. Ressalta-se que esse excesso, caso venha a ser confirmado por novos dados para as semanas seguintes à $14^{a}$, deve ser interpretado como o resultado líquido de efeitos diretos e indiretos da pandemia. Ou seja, ele não representa necessariamente o número estimado de casos de morte por COVID-19 (confirmados e não confirmados), já que a pandemia alterou o contexto social, econômico, comportamental e de atendimento à saúde na cidade, com possíveis reflexos (positivos e negativos) sobre a mortalidade por outras causas naturais.

Figura 7 Desvio (\%) do número esperado de óbitos em 2020, por semana epidemiológica a partir de extrapolação de série histórica de 2014-2019, Belo Horizonte, ambos os sexos

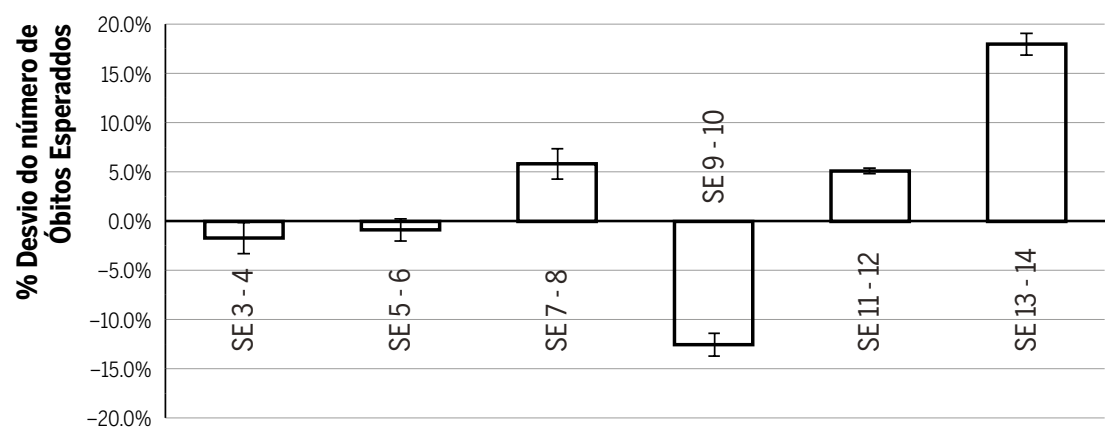

Fonte: SIM/DATASUS/SES-MG.

\section{Discussão}

Este estudo traz um panorama da evolução da pandemia em $\mathrm{BH}$ nos primeiros 80 dias. A análise mostra que a política adotada foi exitosa no controle da pandemia e na capacidade de atendimento do sistema de saúde, durante o período estudado. Até a data da flexibilização, a mediana da 
taxa de transmissibilidade para os dados corrigidos se manteve sempre abaixo de 1,52. Durante os cinco dias que antecederam a flexibilização das atividades econômicas, a mediana das taxas para os casos corrigidos e observados se situou abaixo de 1. Uma taxa de transmissibilidade abaixo de 1 por um período aproximado de uma semana significa que não há transmissão sustentada do vírus e espera-se que o número de novos casos siga uma tendência decrescente (Shim et al., 2020). Além disso, a taxa de ocupação dos leitos enfermaria SUS destinados a COVID-19 em BH manteve-se abaixo de $50 \%$ nesse período.

Em relação à mortalidade, a despeito das limitações atinentes às informações, os resultados apontam um excesso de óbitos naturais observados em relação aos esperados de cerca de $18 \%$ ou 92 óbitos na $13^{\mathrm{a}}$ e $14^{\mathrm{a}}$ semanas analisadas conjuntamente. $\bigcirc$ excesso, se confirmado com dados mais atualizados, corresponderia ao resultado líquido de efeitos diretos e indiretos da pandemia (Banerjee et al., 2020) sobre a mortalidade na cidade. Ou seja, a estimativa não corresponde necessariamente ao número de casos de mortes por COVID-19, uma vez que os óbitos por outras causas podem também ter sido afetados, tanto positivamente quanto negativamente, pelo contexto atual. Apenas um estudo futuro detalhado, que investigue um período mais longo e que examine distribuições por idade, sexo e causas de morte, poderá esclarecer esses efeitos.

Ainda que haja indicação de um excesso de óbitos em BH, ele é relativamente inferior ao estimado para São Paulo e semelhante ao calculado para outras cidades brasileiras (Curitiba e Campinas, por exemplo) no período analisado. A questão a ser ainda respondida para BH é se o excesso de óbitos aumentou nas semanas seguintes à $14^{\mathrm{a}}$ (a partir de início de abril), período em que esse indicador parece ter crescido significativamente em outras cidades brasileiras, como Fortaleza, Rio de Janeiro e Manaus (Fujiwara, 2020).

Três conjuntos de fatores podem explicar o relativo sucesso de $\mathrm{BH}$ no controle à pandemia até o momento da flexibilização. O primeiro refere-se à presença do SUS e sua organização na capital. O princípio da descentralização permitiu autonomia a gestores municipais para dar respostas rápidas e ajustadas às necessidades locais frente à propagação do vírus. Além disso, diversos instrumentos de planejamento e organização da oferta já estavam consolidados no sistema de saúde, particularmente em BH. No município, o SUS tem uma trajetória positiva, destacando-se o processo 
de territorialização dos distritos sanitários e a modernização gerencial com a implantação da gestão plena do sistema na década de 1990. O fortalecimento da atenção primária à saúde por meio da implantação da ESF, a implantação das redes de atenção do SUS BH e as parcerias público-privadas, a partir de 2010, também caracterizam a organização do SUS na capital. Mais recentemente, observou-se a melhoria do acesso, a gestão do cuidado no território e o sistema integrado de gestão e regulação ambulatorial e hospitalar (Teixeira et al., 2014). Soma-se a esse contexto, a gestão do sistema no nível estadual, que tem uma regionalização estruturada, um sistema de redes de urgência já disseminado no Estado e uma central de regulação de leitos única com controle de praticamente todo o fluxo de internações (Parra, 2019). Esses elementos são fundamentais para garantir uma gestão orgânica do sistema capaz de contrabalançar a pressão exercida pela demanda nas diferentes regiões de acordo com a capacidade de oferta. Por ser a capital, BH caracteriza-se como polo macrorregional e do estado, o que poderia acarretar uma pressão maior no sistema do município.

O segundo conjunto de fatores diz respeito à política de enfrentamento da pandemia. A análise realizada no presente artigo das medidas implementadas em $\mathrm{BH}$ evidencia uma gestão com planejamento e articulação estratégica entre as várias dimensões (Peña et al., 2020), diferente da abordagem adotada em nível federal. Conforme analisado por Cimini et al. (2020), o governo federal não adotou nenhum critério técnico para orientar a adoção das medidas de distanciamento social em nível subnacional, tampouco coordenou o timing das ações de achatamento da curva e aumento da capacidade de sistema de saúde, fundamental para evitar o colapso. Foi necessária a intervenção do Supremo Tribunal Federal (STF) para garantir a autonomia dos estados e municípios na determinação das medidas de isolamento social (Rodrigues; Azevedo, 2020).

Essa autonomia não eximia o governo federal, por meio do MS, de estabelecer as diretrizes e coordenação nacional da política de enfrentamento da pandemia. No contexto da pandemia, o papel da política central se justifica por diversos fatores: 1) presença de economias de escala e maior poder de barganha na compra de insumos e equipamentos de proteção; 2) coordenação das políticas de isolamento devido às externalidades entre áreas vizinhas; 3) coordenação do encaminhamento de pacientes, permitindo a otimização da capacidade de oferta, e 4) articulação público-privada em áreas onde a oferta privada tem participação relevante. 
$\mathrm{Na}$ ausência dessa coordenação, BH estabeleceu seu próprio Comitê de Enfrentamento à Epidemia para fundamentar tecnicamente os direcionamentos da política de distanciamento e de flexibilização. Iniciada em 20 de março, com a suspensão temporária de atividades com aglomeração, incluindo comerciais e escolares, e a determinação do teletrabalho na $\mathrm{PBH}$, a primeira fase do distanciamento social teve a duração de dois meses. A adesão da população à política de distanciamento social foi relativamente rápida, alcançando níveis satisfatórios. Antes de o primeiro caso ser registrado em $\mathrm{BH}$, a média de distanciamento situava-se no patamar de $28 \%$ e, três dias após o início das medidas de distanciamento social alcançou $55 \%$, permanecendo no patamar médio de $46 \%$ entre 21 de março e 21 de maio. Essa resposta da população está em consonância com a pesquisa de opinião realizada pelo Instituto Olhar, em parceria com o Centro de Estudos de Criminalidade e Segurança Pública (CRISP-UFMG). Segundo esse estudo, na semana de 30 de abril a 05 de maio, a nota de apoio dos belo-horizontinos ao distanciamento social no município era igual a 9 (entre 0 e 10), enquanto na RMBH era de 8,1. A atuação do governo municipal de $\mathrm{BH}$ no combate à COVID-19 foi muito bem avaliada, 8,5 contra 6,5 na $\mathrm{RMBH}$. Esse resultado contrasta com a avaliação feita pela população belo-horizontina ao governo estadual $(5,4)$ e federal $(2,8)$. $^{3}$

Além do distanciamento, $\mathrm{BH}$ implementou medidas adicionais de contenção, como barreiras sanitárias e distribuição de máscaras de proteção nos aglomerados urbanos. Nas demais capitais, o grau de rigidez das medidas de distanciamento social tem variado significativamente de acordo com a gravidade da epidemia no contexto local (Moraes, 2020b). Com relação às medidas de mitigação, a maioria das capitais tem adotado algum tipo de proteção social. ${ }^{4}$ Belo Horizonte, assim como São Paulo, Rio de Janeiro, Aracaju, Recife, São Luís, João Pessoa e Salvador, destaca-se pela adoção de medidas de acolhimento à população em situação de rua (Silva et al., 2020).

$\mathrm{O}$ terceiro fator para o relativo sucesso de $\mathrm{BH}$ pode estar relacionado à estrutura econômica do município e aos fluxos de bens e serviços com o seu entorno. A cidade apresenta estrutura produtiva concentrada no setor Serviços, que parece possuir maior capacidade de suspensão/paralisação

3 Pesquisa Termômetro da Crise COVID-19, Instituto Olhar. Disponível em: <https://blog. institutoolhar.com.br/termometro-da-crise-COVID-19/>. Acesso em: 10 jun. 2020.

4 Grupo Observatório de Políticas Globais para COVID-19 da UFMG. 
das atividades e de transição para o home-office. A baixa participação da Agricultura e Indústria indica que grande parte da provisão desses bens vem de fora da cidade (Carvalho et al., 2019; Magalhães et al., 2018; Domingues et al., 2011). A RMBH concentra as atividades industriais e parcela significativa da mão-de-obra desse setor reside nessa região, deslocando-se para BH basicamente para o uso de serviços (Miranda; Domingues, 2010). $\mathrm{O}$ fechamento de setores de Serviços em $\mathrm{BH}$ contribuiu para a diminuição desse fluxo, mas manteve o fornecimento de produtos industriais e agrícolas, uma vez que as redes de transporte de produtos não foram significativamente afetadas pelas medidas de contenção da pandemia. Adiciona-se a esse contexto a posição de $\mathrm{BH}$ na hierarquia de cidades brasileiras. Em MG, os deslocamentos para compras de consumo próprio, tais como vestuário, calçados, móveis, eletrodomésticos e eletroeletrônicos, concentram-se em polos regionais dos centros urbanos mais próximos, de forma que o deslocamento para $\mathrm{BH}$ com esses fins é relativamente pequeno, mesmo de cidades da RMBH (IBGE, 2020).

A flexibilização da política de distanciamento impõe novos desafios para o município. A partir de 22 de maio a taxa de transmissibilidade saltou de abaixo de 1 na semana que antecede a flexibilização para o valor mais próximo de 1,5 na primeira semana de junho. Essa mudança no $\mathcal{R}_{t}$ foi percebida no sistema de saúde: a taxa de ocupação dos leitos SUS disponíveis para UTI COVID passou de $42 \%$ para $72 \%$ entre os dias 22 e 06 de junho. Os resultados da simulação mostram que, considerando a oferta e a taxa de ocupação vigentes em 2019, uma taxa de infecção de 1\% comprometeria a capacidade de atendimento dos serviços de alta complexidade tanto em BH como na Micro e Macrorregião de saúde, independentemente da velocidade de propagação do vírus na população. Esse resultado decorre, sobretudo, da elevada taxa de ocupação em leitos UTI historicamente observada, próxima de 100\% (Noronha et al., 2020). O fato de o sistema de saúde de BH ainda não ter colapsado evidencia a capacidade de contenção da propagação do vírus, alcançando uma taxa de $0,73 \%$ ao final desses 80 dias, bem como o planejamento e a organização da oferta, principalmente com adiamento de cirurgias eletivas. Com a flexibilização, estabelecida em quatro fases, o monitoramento diário da evolução da pandemia e da capacidade do sistema, que vem sendo realizado pela SMSA-BH, é fundamental para evitar o colapso do sistema de saúde. Recentemente, no dia 26 de junho, o aumento do número de casos da COVID-19 em BH e 
o consequente aumento nas taxas de ocupação fizeram com que a $\mathrm{PBH}$ retrocedesse no processo de flexibilização, determinando novamente o fechamento do comércio a partir do dia 29 de junho.

O presente estudo apresenta algumas limitações. Devido à indisponibilidade de informações, não foi possível cotejar os dados de casos confirmados com os dados de testagem. A ampla testagem da população é um dos instrumentos mais importantes para o monitoramento da pandemia e para o estabelecimento das políticas de flexibilização (OECD, 2020; Oh et al., 2020). Em segundo lugar, no tocante às medidas institucionais o alcance do artigo é descritivo, não tendo sido realizada avaliação sobre a efetividade e intensidade de sua implementação. Por fim, as associações estabelecidas aqui não permitem a inferência de causalidade.

Entre as variáveis examinadas neste artigo, os óbitos foram os que mais exigiram cuidado metodológico, restringindo o alcance da análise empírica e das conclusões. O Brasil não tem tradição de examinar dados de óbitos em tempo real, já que o sistema requer um período mínimo para registros completos e com a qualidade necessária, tanto no DATASUS quanto no Registro Civil. Além disso, a capacidade das Secretarias Municipais de Saúde em reportar seus casos não é a mesma, o que limita as comparações regionais. Este estudo é provavelmente o primeiro a utilizar dados do SIM-DATASUS para 2020 e anos anteriores, no contexto da pandemia por COVID-19 em MG. A análise, entretanto, foi limitada a BH e às semanas epidemiológicas 03 a 14. Devido às limitações, os dados até a $14^{a}$ semana ainda podem ser alterados pela SMSA-BH. Caso ocorram, o mais provável seria o aumento dos óbitos já registrados. Finalmente, os valores estimados pelo modelo matemático não estão imunes a erros e devem ser tomados com cuidado, já que a predição é feita a partir da extrapolação da experiência passada. Embora haja alta correlação e esse tipo de abordagem metodológica seja utilizado em diferentes países afetados pela pandemia, não há garantia de que o passado se repita no presente.

A despeito dessas limitações, esse artigo contribui ao apresentar conjuntamente as medidas institucionais, a evolução da pandemia e a capacidade da oferta do sistema de saúde em atender à demanda gerada pela COVID-19. A experiência de BH mostra que os instrumentos de gestão têm sido cruciais para o enfrentamento da pandemia. A exemplo do que vem ocorrendo em outros países, enquanto não houver uma vacina ou um medicamento capaz de evitar as complicações da COVID-19 aos pacien- 
tes, o gerenciamento da flexibilização, com possível regressão nas etapas previstas de abertura, deve ser forte o suficiente para evitar que os custos políticos e econômicos de curto prazo se sobreponham à necessidade do distanciamento social (Horton, 2020).

\section{Referências}

ALVES, J. E. D. Diário da Covid-19: BH, a grande cidade que menos sofre com o coronavírus. Projeto Colabora. Publicada em 15 de maio de 2020. Disponível em: <https://projetocolabora.com.br/ods3/bh-a-grande-cidade-que-menos-sofre-com-a-covid-19/>. Acesso em: 16 jun. 2020.

ANDRADE, B. H. S. et al. Eficiência do gasto público no âmbito da saúde: uma análise do desempenho das capitais brasileiras. Revista Paranaense de Desenvolvimento, 38(132), 163 179, 2017.

BASTOS, S. Q. D. A.; GOMES, B. S.; BONIOLI, R. S. Uma avaliação para média complexidade do plano diretor de regionalização da saúde de Minas Gerais (PDR/MG). RDE - Revista de Desenvolvimento Econômico, 2(43), 2019. Acesso em: 21 jun. 2020.

BOTEGA, L. A, ANDRADE, M. V.; GUEDES, G. R. (2020). Brazilian hospitals' performance: An assessment of the unified health system (SUS). Health Care Manag Sci. Disponivel em: $<$ https://doi.org/10.1007/s10729-020-09505-5>. Acesso em: 14 jun. 2020.

BANERJEE, A. et al. Estimating excess 1-year mortality associated with the COVID-19 pandemic according to underlying conditions and age: A population-based cohort study. The Lancet, v. 395, issue 10.238, 2020.

CARVALHO, M. M; MAGALHÃES, A. S.; DOMINGUES, E. P. Impactos econômicos da ampliação do uso de energia solar residencial em Minas Gerais. Nova Economia (UFMG), v. 29 , p. 459-485, 2019.

CDC COVID-19 Response Team. Severe outcomes among patients with coronavirus disease 2019 (COVID-19). MMWR Morb Mortal Wkly Rep; 69:343-346, 2020.

CIMINI, F. et al. Análise das primeiras respostas políticas do governo brasileiro para o enfrentamento da COVID-19 disponíveis no Repositório Global Polimap (n. 013). Nota Técnica Cedeplar, Centro de Desenvolvimento e Planejamento Regional (Cedeplar/UFMG), 2020.

CONASS/CONASEMS (2020). Guia Orientador para o enfrentamento da pandemia na Rede de Atenção à Saúde. COVID-19. Brasília. Disponível em: <http://www.conass.org.br/wp-content/uploads/2020/05/Instrumento-Orientador-Conass-Conasems.pdf>. Acesso em: 16 jun. 2020.

CRODA, J. et al. COVID-19 in Brazil: Advantages of a socialized unified health system and preparation to contain cases. Rev. Soc. Bras. Med. Trop. [online], v. 53, 2020.

DOMINGUES, E. P.; MAGALHÃES, A. S.; BETARELLI, A. Copa do Mundo 2014: impactos econômicos no Brasil, em Minas Gerais e Belo Horizonte. In: HADDAD, E. A.; RAMOS, P. N.; CASTRO, E. A. (Org.). Modelos operacionais de economia regional. Cascais, Portugal: 
Principia Editora, 2011.

DOMINGUES, E. et al. Cenários de isolamento social da COVID19 e impactos econômicos em Minas Gerais. Nota Técnica Cedeplar. Belo Horizonte, 2020. Disponível em: $<$ https://www.cedeplar.ufmg.br/noticias/1243-nota-tecnica-cenarios-de-isolamento-social-da-COVID19-e-impactos-economicos-em-minas-gerais>. Acesso em: 29 jun. 2020.

EMANUEL, E. J. et al. (2020). Fair allocation of scarce medical resources in the time of Covid-19.

FLAXMAN, S. et al. Report 13: Estimating the number of infections and the impact of nonpharmaceutical interventions on COVID-19 in 11 European countries. Imperial College London, 2020.

FREIRE, F. H. M. A. Projeção populacional municipal com estimadores bayesianos, Brasil 2010-2030. In: SAWYER, D. O (Coord.). Seguridade Social Municipais. Projeto Brasil 3 Tempos. Secretaria Especial de Assuntos Estratégicos da Presidência da República (SAE/SG/ PR), Programa das Nações Unidas para o Desenvolvimento Brasil (PNUD Brasil) e Centro Internacional de Políticas para o Crescimento Inclusivo (IPC-IG), 2019.

FUJIWARA, T. Notes (slides) on Estimating Excess Deaths due to COVID-19 in Brazil using the Cartorios Data. Princeton University. Updated: June 10, 2020 First Version: June 4, 2020. Available at: <http://www.princeton.edu/ fujiwara/papers/excess_deaths.pdf $>$. Acesso em: 01 jul. 2020.

HARZHEIM, E. et al. Federal actions to support and strengthen local efforts to combat COVID-19: Primary Health Care (PHC) in the driver's seat. Ciência \& Saúde Coletiva, v. 25, p. 2.493-2.497, 2020.

HE, X. et al. Temporal dynamics in viral shedding and transmissibility of COVID-19. Nature medicine, v. 26, n. 5, p. 672-675, 2020.

HORTON, R. Offline: The second wave. The Lancet, v. 395, n. 10.242, p. 1.960, 2020.

INSTITUTO Brasileiro de Geografia e Estatística (IBGE). Pesquisa Regiões de Influência das Cidades - informações de deslocamentos para serviços de saúde, 2020. Disponível em: $<$ https://www.ibge.gov.br/geociencias/cartas-e-mapas/redes-geograficas/15798-regioes-de-influencia-das-cidades.html>. Acesso em: 11 jun. 2020.

LEON, D. A. et al. COVID-19: A need for real-time monitoring of weekly excess deaths. The Lancet, v. 395, issue 10.234. 2020.

MAGALHAES, A. S. et al. Custo econômico da energia em Minas Gerais: impactos das elevações de tarifas entre 2011 e 2015. Pesquisa e Planejamento Econômico, v. 48, p. 103, 2018.

MIRANDA, R. A.; DOMINGUES, E. P. Commuting to work and residential choices in the metropolitan area of Belo Horizonte. Urban Public Economics Review, v. 12, p. 41-71, 2010.

MORAES, R. F. COVID-19 e medidas legais de distanciamento social: isolamento social, descentralização e análise do período de 11 a 24 e maio de 2020. (Boletim 4). Ipea, 2020(a).

MORAES, R. F. Covid-19 e medidas legais de distanciamento social: isolamento social, gravidade da epidemia e análise do período de 25 de maio a 7 de junho de 2020. (Boletim 5). Ipea, 2020(b).

MORICI, M. C.; BARBOSA, A. C. Q. A gestão de recursos humanos em hospitais do Sistema Único de Saúde (SUS) e sua relação ao modelo de assistência: um estudo em hospitais 
de Belo Horizonte, Minas Gerais. Revista de Administração Pública, 47(1), p. 205-225, 2013.

NORONHA, K. V. M. S. et al. Pandemia por COVID-19 no Brasil: análise da demanda e da oferta de leitos hospitalares e equipamentos de ventilação assistida segundo diferentes cenários. Cadernos de Saúde Pública, 36(6), 2020.

OECD. Testing for COVID-19: A way to lift confinement restrictions, 2020.

$\mathrm{OH}$, J. et al. National response to COVID-19 in the Republic of Korea and lessons learned for other countries. Health Systems \& Reform, v. 6, n. 1, e-1753464, 2020.

OLIVEIRA, W. K. et al. Como o Brasil pode deter a COVID-19. Epidemiologia e Serviços de Saúde, 29(2), e2020044. Epub April 27, 2020. Disponível em: <https://dx.doi.org/10.5123/ s1679-49742020000200023>. Acesso em: 16 jun. 2020.

PARRA, R. D. V. Regulação assistencial: promoção da equidade no acesso às internações hospitalares de urgência no âmbito do Sistema Único de Saúde de Minas Gerais. 74 p. Monografia de conclusão de Curso (Especialização em Administração Pública Planejamento e Gestão Governamental) - Fundação João Pinheiro, Escola de Governo Professor Paulo Neves de Carvalho, 2019. Disponível em: <http://monografias.fjp.mg.gov.br/handle/123456789/2683>. Acesso em: 06 jul. 2020.

PARREIRAS, M. Minas lidera no controle da COVID-19; BH é vice-líder entre capitais. Estado de Minas Gerais, 2020. Disponível em: <https://www.em.com.br/app/noticia/gerais/2020/06/06/interna_gerais,1154312/minas-lidera-no-controle-da-covid-19-bh-e-vice-lider-entre-capitais.shtml>. Acesso em: 29 jun. 2020.

PEÑA, S. et al. PoliMap: A taxonomy proposal for mapping and understanding the global policy response to COVID-19, 2020.

RIBEIRO, L.; BERNARDES, A. T. Atualização da estimativa de subnotificação em casos de hospitalização por Síndrome Respiratória Aguda e confirmados por infecção por COVID-19 no Brasil e estimativa para Minas Gerais. Nota Técnica Cedeplar. Centro de Desenvolvimento e Planejamento Regional (Cedeplar/UFMG), 2020.

RODRIGUES, J. N.; AZEVEDO, D. A. D. Pandemia do coronavírus e (des)coordenação federativa: evidências de um conflito político-territorial. Espaço e Economia. Revista Brasileira de Geografia Econômica, n. 18, 2020.

SHIM, E. et al. Transmission potential and severity of COVID-19 in South Korea. International Journal of Infectious Diseases, v. 93, p. 339-344, 2020.

SILVA, T. D.; NATALINO, M.; PINHEIRO, M. B. População em situação de rua em tempos de pandemia: um levantamento de medidas municipais emergenciais. (Boletim 74). Ipea, 2020.

SILVA, F. F. da. Análise da eficiência do gasto público em ações e serviços de saúde nas capitais brasileiras. 2018. 116 f.: il. Dissertação (Mestrado em Ciências Contábeis) - Universidade Federal do Rio Grande do Norte, Centro de Ciências Sociais Aplicadas, Programa de Pós-Graduação em Ciências Contábeis. Natal, RN, 2018.

STARLING, H. O ano em que Belo Horizonte enfrentou a peste. UFMG. Noticias. Opinião. 16 abr. 2020. Disponível em: <https://ufmg.br/comunicacao/noticias/o-ano-em-que-belo-horizonte-enfrentou-a-peste>. Acesso em: 13 jun. 2020.

TEIXEIRA, M. G.; RATES, S. M. M.; FEREIRA, J. M. (Org.). O coletivo de uma construção: o Sistema Único de Saúde de Belo Horizonte. Belo Horizonte: Rona Editora; 2014. 
TSAI, T. C.; JACOBSON, B. H.; JHA, A. K. American Hospital Capacity and Projected Need for 230 COVID-19 Patient Care. Health Affairs Blog 2020; (March 17. Available at: $<$ https://www.healthaffairs.org/do/10.1377/hblog20200317.457910/full/>. Acesso em: 13 jun. 2020.

TURCI, M. A.; LIMA, M. F.; MACINKO, J. A. Avaliação da Atenção Primária e a percepção do usuário sobre a qualidade da assistência: um estudo em cidade brasileira. APS em Revista, 1(1), 3-17, 2019.

VASCONCELOS, M. C.; SILVA, C. L. da. Uma avaliação do sistema único de saúde nas capitais brasileiras: sugestões para a criação de políticas públicas. GCG: Revista Globalización, Competitividad y Gobernabilidad, 12(3), 49-63, 2018.

WORLD HEALTH ORGANIZATION (WHO). Responding to community spread of COVID-19: Interim guidance, 7 Mar. 2020. World Health Organization, 2020.

\section{Sobre os autores}

Mônica Viegas Andrade - mviegas@cedeplar.ufmg.br

Cedeplar, Universidade Federal de Minas Gerais, Belo Horizonte, Minas Gerais, Brasil. ORCID: https://orcid.org/0000-0002-6821-1598.

Kenya Noronha-knoronha@cedeplar.ufmg.br

Cedeplar, Universidade Federal de Minas Gerais, Belo Horizonte, Minas Gerais, Brasil. ORCID: https://orcid.org/0000-0002-7174-6710.

Cassio Maldonado Turra-turra@cedeplar.ufmg.br

Cedeplar, Universidade Federal de Minas Gerais, Belo Horizonte, Minas Gerais, Brasil. ORCID: https://orcid.org/0000-0003-4051-3567.

GilvanGuedes-grguedes@cedeplar.ufmg.br

Cedeplar, Universidade Federal de Minas Gerais, Belo Horizonte, Minas Gerais, Brasil. ORCID: https://orcid.org/0000-0001-8231-238X.

FernandaCimini-fcimini@cedeplar.ufmg.br

Cedeplar, Universidade Federal de Minas Gerais, Belo Horizonte, Minas Gerais, Brasil. ORCID: https://orcid.org/0000-0003-2170-6443.

Leonardo Costa Ribeiro - leonardocostaribeiro@gmail.com

Cedeplar, Universidade Federal de Minas Gerais, Belo Horizonte, Minas Gerais, Brasil. ORCID: https://orcid.org/0000-0002-7772-9313.

Américo Tristão Bernardes-atb@iceb.ufop.br Departamento de Física, Universidade Federal de Outro Preto, Ouro Preto, Minas Gerais, Brasil. ORCID: https://orcid.org/0000-0003-1736-7215.

Edson Domingues - epdomin@cedeplar.ufmg.br

Cedeplar, Universidade Federal de Minas Gerais, Belo Horizonte, Minas Gerais, Brasil. ORCID: https://orcid.org/0000-0002-7640-6010.

Mirian Martins Ribeiro - miriannina@gmail.com

Departamento de Economia, Universidade Federal de Outro Preto, Mariana, Minas Gerais, Brasil. ORCID: https://orcid.org/0000-0002-4256-220X.

Laura de Almeida Botega - almeidalaura140@gmail.com

Cedeplar, Universidade Federal de Minas Gerais, Belo Horizonte, Minas Gerais, Brasil. ORCID: https://orcid.org/0000-0001-6030-4100.

Lucas Resende de Carvalho-lucasrc@cedeplar.ufmg.br

Cedeplar, Universidade Federal de Minas Gerais, Belo Horizonte, Minas Gerais, Brasil. ORCID: https://orcid.org/0000-0002-3618-3967.

Daniel Nogueira -danielns91@gmail.com

FACE, Universidade Federal de Minas Gerais, Belo Horizonte, Minas Gerais, Brasil.

ORCID: https://orcid.org/0000-0002-3206-7782. 
JuliaAlmeida Calazans - jucalazans@cedeplar.ufmg.br

Cedeplar, Universidade Federal de Minas Gerais, Belo Horizonte, Minas Gerais, Brasil. ORCID: https://orcid.org/0000-0002-6215-3251.

Nayara AbreuJulião-najuliao@cedeplar.ufmg.br

Cedeplar, Universidade Federal de Minas Gerais, Belo Horizonte, Minas Gerais, Brasil. ORCID: https://orcid.org/0000-0002-3223-9468.

Aline de Souza - asouza@cedeplar.ufmg.br

Cedeplar, Universidade Federal de Minas Gerais, Belo Horizonte, Minas Gerais, Brasil. ORCID: https://orcid.org/0000-0001-8860-9643.

ValériaAndrade Silva-valeriaandrade@cedeplar.ufmg.br

FACE, Universidade Federal de Minas Gerais, Belo Horizonte, Minas Gerais, Brasil.

ORCID: https://orcid.org/0000-0003-3316-7459.

Victor Hugo Lima - vhln10@ufmg.br

FACE, Universidade Federal de Minas Gerais, Belo Horizonte, Minas Gerais, Brasil.

ORCID: https://orcid.org/0000-0001-6712-2166.

Jéferson Pereira Andrade-jeferson@epopea.com.br

Departamento de Estatística, Universidade Federal de Minas Gerais, Belo Horizonte, MG, Brasil.

ORCID: https://orcid.org/0000-0002-0731-3427.

Monique Felix Ferreira - moniquefelix@outlook.com

Secretaria de Estado de Saúde de Minas Gerais, Belo Horizonte, Minas Gerais, Brasil.

ORCID: https://orcid.org/0000-0003-2513-4382.

Reinaldo Onofre dos Santos - reinaldosantos80@gmail.com

Secretaria Municipal de Planejamento, Belo Horizonte, Minas Gerais, Brasil.

ORCID: https://orcid.org/0000-0001-6762-9100.

Jomara Alves da Silva - jomara.alves@pbh.gov.br

Secretaria Municipal de Saúde, Belo Horizonte, Minas Gerais, Brasil.

ORCID: https://orcid.org/0000-0001-9595-4138.

Os autores agradecem ao Eugênio Vilaça Mendes a leitura cuidadosa deste artigo e a InLoco pela cessão dos dados de isolamento. Mônica Viegas, Kenya Noronha, Cassio Turra e Gilvan Guedes agradecem ao CNPq pela bolsa de produtividade. Mônica Viegas agradece a Fapemig pelo suporte do Programa de Pesquisador Mineiro. O presente trabalho foi realizado com apoio da Coordenação de Aperfeiçoamento de Pessoal de Nível Superior - Brasil (CAPES) - Código de Financiamento 001. Este artigo também recebeu contribuição da Rede Brasileira de Pesquisas sobre Mudanças Climáticas Globais, convênio FINEP/ Rede CLIMA 01.13.0353-00 e da FAPEMIG (Processo APQ-01553-16).

\section{Sobre 0 artigo}

Recebido em 17 de junho de 2020. Aprovado em 14 de julho de 2020. 